OPEN ACCESS

Edited by:

Alessandra Castegna University of Bari Aldo Moro, Italy

Reviewed by:

Georg F. Weber,

University of Cincinnati, United States Lorena Pochini,

University of Calabria, Italy

${ }^{*}$ Correspondence: Silvia Deaglio

silvia.deaglio@unito.it Valentina Audrito

valentina.audrito@unito.it

Specialty section: This article was submitted to

Cancer Metabolism,

a section of the journa

Frontiers in Oncology

Received: 27 November 2019 Accepted: 02 March 2020

Published: 19 March 2020

Citation:

Audrito V, Messana VG and Deaglio S (2020) NAMPT and NAPRT: Two

Metabolic Enzymes With Key Roles in

Inflammation. Front. Oncol. 10:358.

doi: 10.3389/fonc.2020.00358

\section{NAMPT and NAPRT: Two Metabolic Enzymes With Key Roles in Inflammation}

\author{
Valentina Audrito*, Vincenzo Gianluca Messana and Silvia Deaglio* \\ Laboratory of Tumor Immunogenetics, Department of Medical Sciences, University of Turin, Turin, Italy
}

Nicotinamide phosphoribosyltransferase (NAMPT) and nicotinate phosphoribosyltransferase (NAPRT) are two intracellular enzymes that catalyze the first step in the biosynthesis of NAD from nicotinamide and nicotinic acid, respectively. By fine tuning intracellular NAD levels, they are involved in the regulation/reprogramming of cellular metabolism and in the control of the activity of NAD-dependent enzymes, including sirtuins, PARPs, and NADases. However, during evolution they both acquired novel functions as extracellular endogenous mediators of inflammation. It is well-known that cellular stress and/or damage induce release in the extracellular milieu of endogenous molecules, called alarmins or damage-associated molecular patterns (DAMPs), which modulate immune functions through binding pattern recognition receptors (PRRs), such as Toll-like receptors (TLRs), and activate inflammatory responses. Increasing evidence suggests that extracellular (e)NAMPT and eNAPRT are novel soluble factors with cytokine/adipokine/DAMP-like actions. Elevated eNAMPT were reported in several metabolic and inflammatory disorders, including obesity, diabetes, and cancer, while eNAPRT is emerging as a biomarker of sepsis and septic shock. This review will discuss available data concerning the dual role of this unique family of enzymes.

Keywords: inflammation, cancer, signaling, metabolism, DAMPs, NAMPT, NAPRT, TLRs

\section{INTRODUCTION}

One of the key roles of the innate immune system is to initiate immune responses against invasive pathogens. Pathogen-associated molecular patterns (PAMPs) include sugars/lipoproteins or nucleic acids [i.e., bacterial DNA as unmethylated repeats of dinucleotide $\mathrm{CpG}$, double-stranded (ds) or single-stranded (ss) RNA] $(1,2)$. PAMPs can initiate immune responses through the activation of classical pattern recognition receptors (PRRs), among which there are toll-like receptors (TLRs), NOD-like receptors (NLRs), retinoic acid inducible gene I (RIG- I)-like receptors (RLRs), C-type lectin receptors (CLRs), multiple intracellular DNA sensors, and other non-PRRs DAMPs receptors $(2-4)$. However, these receptors can be engaged also by endogenous ligands. It is now largely accepted that cells in conditions of hypoxia, acidosis, redox imbalance, hypertonic/hypotonic stress, and intracellular ion or cytoskeleton perturbations, can release small endogenous molecules called damage-associated molecular patterns (DAMPs) or sometimes "danger signals" or "alarmins," triggering immune responses through the activation of PRRs (4-6). Intriguingly, many of these DAMPs have a well-characterized intracellular function and have been serendipitously identified in the extracellular space where they initiate inflammatory responses, independently of pathogen 
infection, a phenomenon referred to as sterile inflammation $(4,7,8)$. Similar to pathogen-induced inflammation, DAMPs can prime neutrophils, macrophages, and dendritic cells (DCs), but also non-immune cells, including endothelial and epithelial cells and fibroblasts (7). Activation of these cells leads to the production of several cytokines and chemokines, which in turn recruit inflammatory elements and trigger adaptive immune responses. Although sterile inflammation plays an essential role in tissue repair and regeneration, unresolved chronic inflammation is deleterious to the host leading to the development of metabolic, neurodegenerative, autoimmune disorders, and cancer (4).

Since their original definition as DAMPs in 2003, the list of endogenous molecules are increased considerably (4) and now includes high-mobility group box 1 protein (HMGB-1), heat shock proteins (HSPs), histone and extracellular matrix components (for example, hyaluronic acid and biglycan). All these molecules exert pro-inflammatory functions through binding to TLRs. HMGB-1 is among the most studied DAMPs. It is a nuclear DNA binding protein that can be found in the extracellular space not only as a consequence of necrosis, but also through dedicated secretion mechanisms $(9,10)$. Extracellularly, HMGB-1 elicits pro-inflammatory effects linked to consequent TLR4 binding and activation of the nuclear-factor kappa B (NF$\mathrm{kB})$ signaling pathway $(11,12)$. In animal models, HMGB-1 is as a late mediator of lethal systemic inflammation, involved in delayed endotoxin lethality (13). Others DAMPs include F-actin, Sin3A associated protein 130 (SAP130), $\beta$-glucosylceramide and N-glycans binding to CLRs; monosodium urate (MSU) crystals, cholesterol crystals, $\beta$-amyloid $(\mathrm{A} \beta)$, and adenosine $5^{\prime}$ triphosphate (ATP) that activate NLRP3 inflammasome (4). In addition, numerous cytokines [i.e., interleukin (IL)- $1 \beta$, tumor necrosis factor (TNF), and type I interferon (IFN-I)], proinflammatory proteins, such as interferon-induced protein 35 , and bioactive lipids like lysophospholipids, are referred as “inducible DAMPs” or “conditional DAMPs" (14).

Nucleotides and nucleosides, for long time considered simply electron-shuttling agents involved in supporting energy metabolism, are gaining interest together with the network of enzymes that control their synthesis and degradation. Interestingly, while all these factors have a well-characterized intracellular function, they can be released in the extracellular space, where they bind and activate different sets of cellular receptors, including purinergic and PRRs. For example, ATP a key intracellular energy molecule, can be massively released by passive leakage when cells become injured, stressed, or even necrotic, acting as a DAMP (15). Extracellular ATP and its derivative nucleotides (adenosine, AMP, ADP) synthesized by endonucleotidases achieve many of their effects through purinergic receptors, via inflammatory cascades and the production of proinflammatory cytokines $(16,17)$. Among the enzymes involved in nicotinamide adenine dinucleotide (NAD) synthesis, nicotinamide phosphoribosyltransferase (NAMPT) - the focus of this review-emerges as new mediator of inflammation. Intracellularly, it catalyzes the first and ratelimiting step in the biosynthesis of NAD from nicotinamide (Nam) (18, 19). Increased eNAMPT levels are reported in conditions of acute or chronic inflammation (18, 2025). eNAMPT effects are mostly linked to the activation of an inflammatory signature mainly in macrophages, with recent data suggesting that it binds TLR4, therefore adding the enzyme to the number of "danger" signals activating this receptor (26). NAMPT is structurally and functionally related to a second NAD-biosynthetic enzyme (NBE), i.e., nicotinate phosphoribosyltransferase (NAPRT), which is rate-limiting in the NAD salvage pathway that starts form nicotinic acid (Na) (27-29). Our group recently discovered the presence of NAPRT in extracellular fluids (eNAPRT), highlighting a role also for this enzyme as a ligand for TLR4.

This review summarizes the current knowledge on NAMPT and NAPRT, as intracellular NBEs involved in the regulation/reprogramming of cellular metabolism, and as cytokines/DAMPs in the extracellular environment. Lastly, we will discuss the role of these enzymes especially in relation to the development of inflammatory conditions, including cancer, and their potential therapeutic values.

\section{NAD LEVELS MODULATE CELLULAR TRANSCRIPTIONAL RESPONSES AND METABOLIC ADAPTATION}

Our knowledge on NAD biology has grown exponentially over the past few years, including biosynthetic and degrading pathways. A general decrease in cellular NAD is described in many age-related diseases, whereas increased NAD levels are associated to inflammatory conditions, including cancer. Figure 1 illustrates the main NAD-biosynthetic and -consuming pathways, as well as the crosstalk between intracellular (i)NAD and eNAD.

\section{NAD: Energy Cofactor}

As energetic co-enzyme, NAD is essential as electron acceptor donor in various metabolic pathways including cytosolic glycolysis, serine biosynthesis, tricarboxylic acid cycle (TCA), oxidative phosphorylation, as well as cell redox state homeostasis redox reactions $(30,31)$. Cofactor of almost 300 dehydrogenase, NAD is primarily used during glycolysis in the sixth step of the enzymatic chain by glyceraldehyde phosphate dehydrogenase (GAPDH) and at the end of the process by lactate dehydrogenase $(\mathrm{LDH})$, catalyzing the interconversion of pyruvate and lactate and simultaneously of NADH and NAD. The final glycolytic product pyruvate, can be metabolized to produce acetylCoA by the pyruvate dehydrogenase complex (PDC), a reaction accompanied by NAD reduction to NADH (32). During the TCA cycle, NAD is reduced to NADH moieties in several key steps by isocitrate dehydrogenase (IDH), oxoglutarate dehydrogenase (OGD), and malate dehydrogenase (MDH). NADH produced in all these reactions, working as electron equivalent redistributor, is used by the electron transport chain (ETC) to generate ATP (33).

The ratio between $\mathrm{NAD} / \mathrm{NADH}$ and their relative phosphorylated form (NADP/NADPH), are also critical for enzymatic defense systems against oxidative stress, regulating 


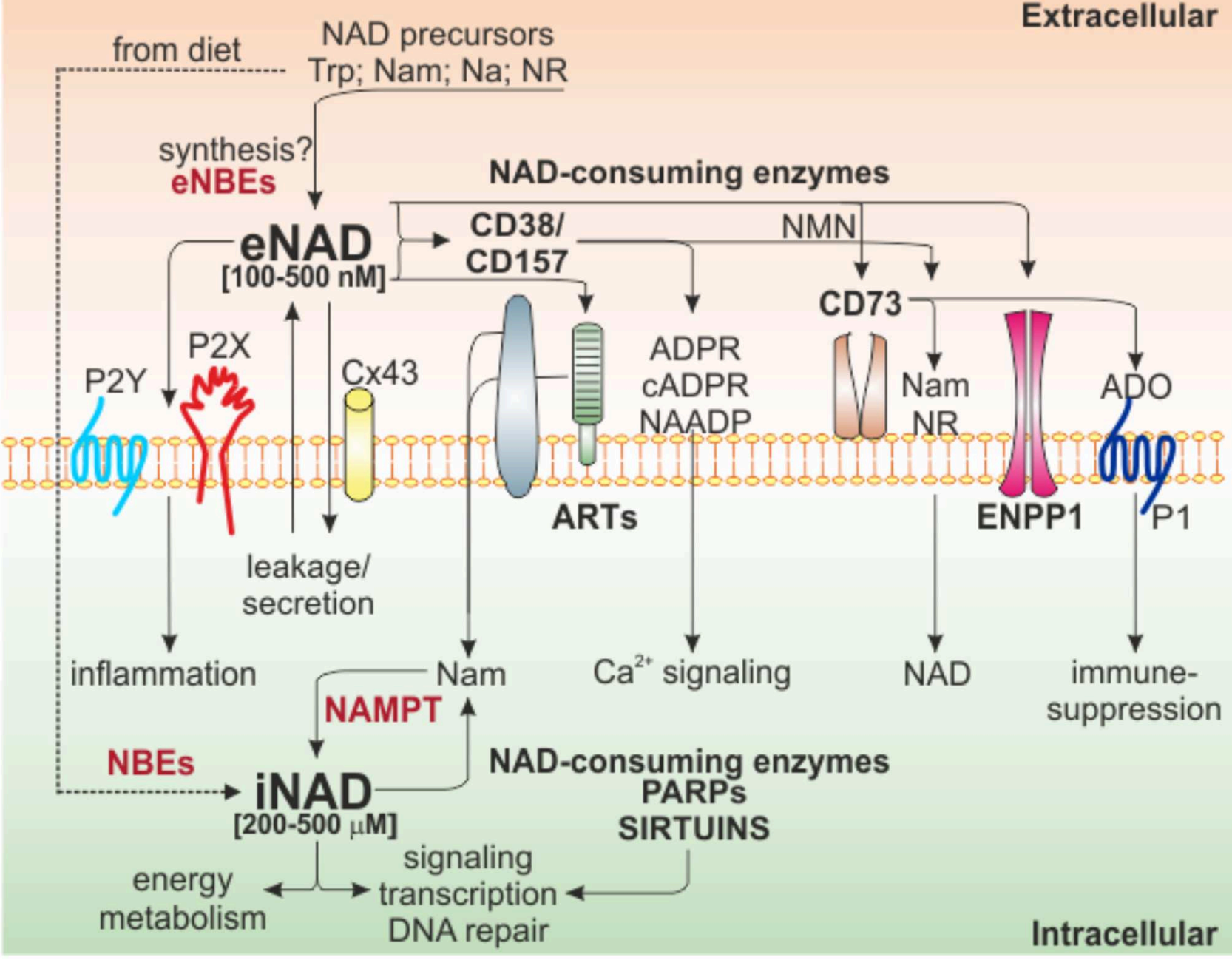

FIGURE 1 | Intra/extra NAD interconnections and NAD-metabolizing enzymes. Schematic representation of the network of NAD-metabolizing cell surface and intracellular enzymes and their products. Several NAD precursors derived from diet can be internalized to generate iNAD, via NBE activities, to support energy metabolism, signaling, and other biological processes through the activities of intracellular NAD-consuming enzymes (PARPs and Sirtuins). These enzymes release Nam that, in turn, via NAMPT-dependent salvage pathway, support NAD production. Once in the extracellular space because of secretion/leakage, via Cx43, or because of direct extracellular synthesis from precursors (not confirmed), eNAD can function by binding purinergic receptors (P2Y, P2X), an event that leads to intracellular signaling and inflammatory conditions. Alternatively, eNAD can also be metabolized by a series of ecto-enzymes of the cell surface (CD38/CD157, ARTs, CD73, ENPP1) generating different metabolites (CADPR, ADPR, and NAADP) involved mainly in $\mathrm{Ca}^{2+}$-signaling. The end product of the reaction, adenosine, can modify signal transduction by acting on P1 purinergic receptors, generally leading to immunosuppression. In the square brackets are indicated the range of iNAD

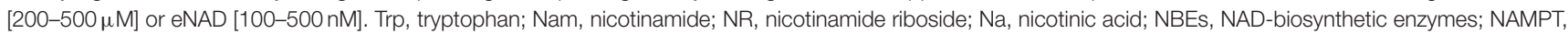
nicotinamide phosphoribosyltransferase; ARTs, mono adenosine diphosphate (ADP)-ribose transferases; PARPs, poly ADP-ribose polymerases; Cx43, connexin 43; ADPR, ADP ribose; CADPR, cyclic ADP ribose; NAADP, nicotinic acid adenine dinucleotide phosphate; NMN, nicotinamide mononucleotide; ADO, adenosine; ENPP1, ectonucleotide pyrophosphatase/phosphodiesterases.

redox homeostasis through the main cellular scavenging systems which are the glutathione (GSH/GSSG) and the thioredoxinmediated (Trx-SH/Trx-SS) mechanisms (34-37). In this context, $\mathrm{NADPH}$ is the indispensable reducing agent for ROS elimination and redox homeostasis, primarily produced by glucose-6phosphate dehydrogenase (G6PD) and -phosphogluconate dehydrogenase (6PGD) in the pentose phosphate pathway (36).

\section{NAD: A Pleiotropic Signaling Molecule}

Independently of its redox properties, NAD is also the substrate of enzymes with fundamental roles in gene expression and cell signaling (38). In these reactions, NAD is cleaved at the glycosidic bond between Nam and ADP-ribose acquiring the characteristic of signaling molecule (27).

The large family of NAD consuming enzymes includes mono adenosine diphosphate (ADP)-ribose transferases 
(ARTs) and poly ADP-ribose polymerases (PARPs), the NADdependent deacetylases, sirtuins (SIRT1-7), and the cyclic ADP-ribose hydrolases, NAD glycohydrolases, ectonucleotide pyrophosphatase/phosphodiesterases and ecto-5'-nucleotidase (CD38/CD157 and ENPP1/CD73) (19, 39, 40) (Figure 1).

Through their functional activities of post-translational modifications (ADP-ribosylation and deacetylation), or through the modulation of $\mathrm{Ca}^{2+}$ signaling, these enzymes regulate gene transcription, cell differentiation, cell cycle progression, circadian rhythm, DNA repair, chromatin stability, cell adaptation to stress signals, and immune responses $(41,42)$. Therefore, PARPs and sirtuins represent connecting elements between the metabolic state of a cell and its signaling and transcriptional activities (43).

\section{Extracellular NAD and Its Biological Role}

The eNAD concentration is in the range of $100-500 \mathrm{nM}$, considerably lower than its intracellular levels $(200-500 \mu \mathrm{M})(39$, 44-46). eNAD and iNAD levels are highly linked, due to intraextra membrane transport of NAD precursors, intermediates of reaction and NAD itself (47). The canonical view is that NAD is unable to cross lipid bilayers, but it enters the cell using dedicated NAD transporters, such as connexin 43 (Cx43) channels, or exits through exocytosis $(45,48-50)$. In addition, conditions of environmental stress can induce NAD release (51-53). On the other hand, whether there is direct eNAD synthesis remains controversial (39) (Figure 1), despite the presence of extracellular precursors and biosynthetic enzymes. Specifically, it is known that among the different forms of vitamin B3 (NAD precursor), transport of $\mathrm{Na}$ is mediated by membrane carrier systems potentially including either a $\mathrm{pH}$-dependent anion antiporter or a proton cotransporter $(54,55)$. Nam is present extracellularly and its uptake is possible either as direct transport in intact form or converted to salvage pathway metabolites. However, NAMPT's substrates ATP and 5-phosphoribosyl-1-pyrophosphate (PRPP) were shown to be unavailable in sufficient quantities in the extracellular space (56) to support direct eNAD generation.

eNAD can bind different subtypes of purinergic $\mathrm{P} 2$ receptors, including P2Y11, leading to the opening of L-type $\mathrm{Ca}^{2+}$ channels and activation of a cAMP/cADPR/[ $\left[\mathrm{Ca}^{2+}\right] \mathrm{i}$ signaling cascade, ultimately causing increased proliferation and migration (57). In $\mathrm{T}$ cells and monocytes, $\mathrm{P} 2 \mathrm{X} 7$ receptor activation generally results in $\mathrm{Ca}^{2+}$ internalization, opening a non-selective, large membrane pore, causing cell death $(58,59)$. eNAD also acts as a neurotransmitter, released by stimulated terminals of mammalian central nervous system and peripheral nervous system neurons, binding to post-synaptic P2Y1 receptors, similar to $\operatorname{ATP}(60)$.

The very low levels of eNAD are due to its rapid metabolism/degradation by NAD-catabolic enzymes present on the surface of the cell (61), suggesting that also NAD metabolites may mediate cellular responses in the extracellular environment.

eNAD is degraded by three main classes of specific ectoenzymes: CD38 and CD157 (62, 63), ARTs (64), ENPP1 and CD73 $(61,65,66)$. NADase, ENPP1 and CD73 can lead to the formation of adenosine (ADO), a potent immunosuppressant factor, independently of the activity of $\operatorname{CD} 39(61,67,68)$. Beside generating $\mathrm{ADO}, \mathrm{eNAD}$ can be degraded to nicotinamide mononucleotide (NMN) by CD38, generating Nam which can cross plasma membranes and be re-converted to NAD through NAMPT and NMN adenylyltransferase (NMNAT) (69). On the other side, NMN can be also used by CD73, which generates nicotinamide riboside (NR) $(66,70)$, that, likely through equilibrative nucleoside transporters (ENTs), can be imported as NAD precursor $(71,72)$ (Figure 1). Recently, Slc12a8 was identified as specific NMN transporter (73), suggesting that NMN can be internalized without conversion to NR. Studies on cell type expression pattern of this transporter will clarify this possibility.

\section{NAD BIOSYNTHESIS: THE ENZYMATIC FUNCTIONS OF NAMPT AND NAPRT}

NAD turnover within the cell is dynamic, displaying circadian oscillations that are regulated by the core clock machinery CLOCK:BMAL1 (74, 75). Total intracellular levels are maintained between 200 and $500 \mu \mathrm{M}$, depending on the cell type or tissue, increasing in response to different stimuli (43). NAD homeostasis is the result of the balance between a number of NAD-consuming reactions and NAD-biosynthetic routes, via three distinct pathways: the de novo biosynthetic pathway, the Preiss-Handler pathway, and the salvage pathway, as reviewed in Houtkooper et al. (27), Ruggieri et al. (29), and Audrito et al. (42) and illustrated in Figure 2.

Specifically, de novo NAD biosynthesis starts with the catabolism of the amino acid tryptophan to kynurenine by indoleamine-2,3-dioxygenase. Kynurenine is then metabolized through the kynurenine pathway to quinolinic acid (QA), which is converted by quinolate phosphoribosyltransferase (QPRT), rate-limiting enzyme, to Na mononucleotide (NaMN). The Preiss-Handler pathway metabolizes kynurenine pathwayderived $\mathrm{NaMN}$ or diet-derived $\mathrm{Na}$, or $\mathrm{Na}$ as a product of $\mathrm{Nam}$ deamidation by intestinal flora (76) to NAD, via NAPRT ratelimiting activity. In the salvage pathway, NAMPT metabolizes Nam and PRPP to NMN in a rate limiting step, which is then converted into NAD. In a further salvage route, NR, derived from diet, can be used by nicotinamide riboside kinase (NRK), to generate NAD (Figure 2).

Quantitatively, the Nam salvage pathway is the most relevant in mammalian cells. Several lines of evidence support this observation. First, Nam is the most abundant NAD precursor in the bloodstream (39), and can be easily introduced by diet (vitamin B3). Second, Nam is a by-product of all NADmetabolizing enzymes activity, increasing its availability (77). Third, the rate limiting enzyme NAMPT (EC 2.4.2.12) is expressed in all mammalian tissues (78), as detailed below. Linked to this, NAMPT gene deletion in mice is embryonically lethal (79), suggesting the importance of this route to regenerate $\mathrm{NAD}$. In this pathway, Nam N-methyltransefase (NNMT) recently emerged as an evolutionarily conserved regulator of Nam availability. In fact, NNMT N-methylates Nam preventing its accumulation and inhibition of NAD-consuming enzymes, while on the other side, limiting its availability to NAMPT $(80,81)$. 


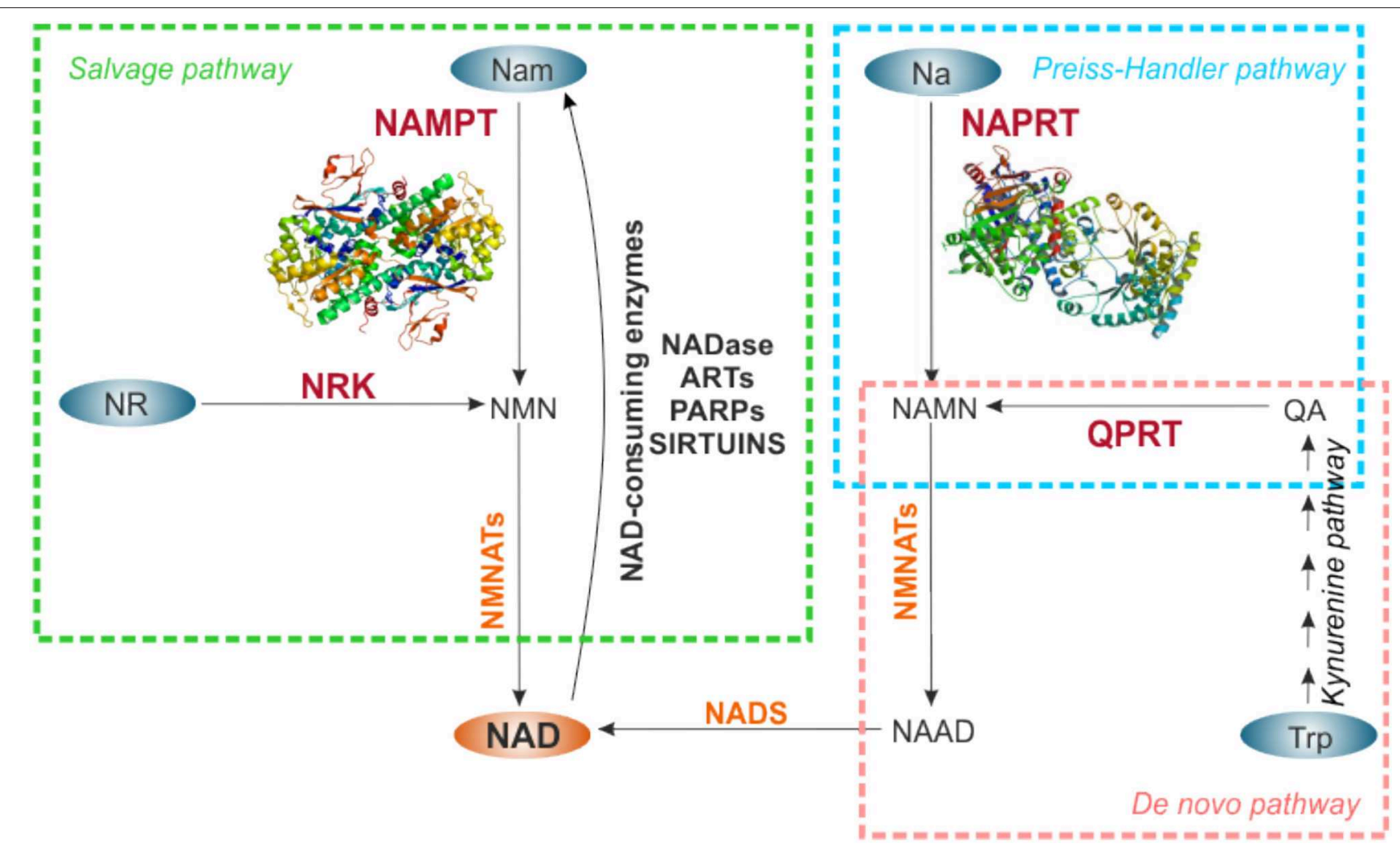

FIGURE 2 | NAD biosynthetic pathways. NAD can be synthetized de novo starting from Trp (pink rectangle), or through salvage routes from Nam and NR (green rectangle), or metabolizing $\mathrm{Na}$ in the Preiss-Handler pathway (light blue rectangle). NAD-precursors are indicated in the blue ovals. The rate-limiting enzymes of each biosynthetic pathway are indicated in red, the other enzymes involved in the reactions in orange. For NAMPT and NAPRT crystal structures are shown. NAD synthesized from Nam via NAMPT is in turn used by NAD-consuming enzyme activities that release Nam, making it available for continuous NAD regeneration. NAMPT, nicotinamide phosphoribosyltransferase; NAPRT, nicotinate phosphoribosyltransferase; NRK, nicotinamide riboside kinase; QPRT, quinolinate phosphoribosyltransferase; NMNATs, nicotinamide mononucleotide adenylltransferases; NADS, NAD synthase; Nam, nicotinamide; NR, nicotinamide riboside; Na, nicotinic acid; Trp, tryptophan; QA, quinolinic acid; NMN, nicotinamide mononucleotide; NAMN, nicotinate mononucleotide; NAAD, nicotinate adenine dinucleotide; NADase, NAD-glycohydrolase; ARTs, mono adenosine diphosphate (ADP)-ribose transferases; PARPs, poly ADP-ribose polymerases.

The functional NAMPT forms a homodimer to catalyze the conversion of Nam and PRPP to NMN. Structural and site-directed mutagenesis studies by Khan et al. demonstrated that Asp219 is fundamental in defining the substrate specificity of NAMPT (82). Wang et al. showed that NAMPT has an autophosphorylation activity and hydrolyzes ATP. Autophosphorylation can increase its enzymatic activity (83). Recently, NAMPT was found to be a direct substrate of SIRT6 deacetylation, a post-translational mechanism that upregulates its enzymatic activity (84). On the contrary, mutations of His247, a central conserved residue in the active site of the enzyme, significantly decreases or abolishes NAMPT enzymatic activity (83).

NAPRT (EC 2.4.2.11) catalyzes the conversion of $\mathrm{Na}$ and PRPP to NaMN and pyrophosphate (PPi). The enzyme, originally named NaMN pyrophosphorylase, was first described by Handler in human erythrocytes, where it increases NAD levels (85).

NAPRT activity is more tissue-specific. Although enzyme activity can be detected in most mouse tissues (86), Na acts as a more efficient precursor than Nam in mice liver, intestine, heart and kidney (87). Furthermore, $\mathrm{Na}$ is more efficient than Nam in raising NAD levels in cells exposed to oxidative stress $(56,85,88)$.

Contrary to NAMPT, NAPRT is not inhibited by NAD, which explains its significantly higher efficiency in raising NAD levels in vivo $(56,89)$. Moreover, NAPRT is strongly activated by phosphate (85), while ATP behaves as an allosteric modulator of the enzyme $(29,85,90)$.

In 2015 Marletta et al. resolved the structure of human (h)NAPRT, highlighting a high degree of structural homology between the human and the bacterial NaPRTases due to evolutionary adaptation (91). As with NAMPT, the functional NAPRT enzyme works as dimers, and despite sharing very limited sequence similarity, hNAPRT shows a molecular fold that closely resembles that firstly described for hNAMPT (83). This opened new hypotheses of shared motifs in NAMPT and NAPRT involved in the binding of extracellular proteins to the receptor, as described in section eNAMPT Functions.

The presence of these multiple NAD biosynthetic routes most likely reflects differences in tissue distribution and/or intracellular compartmentalization of NBEs $(39,46,76,92,93)$. Our group recently showed that NAMPT and NAPRT are mainly 
located in cytoplasm and nucleus, while NRK is more expressed in mitochondria, impacting on iNAD levels and response to NAMPT inhibitors $(39,46,76,92,93)$.

\section{Identification, Characterization, and Expression of NAMPT and NAPRT NAMPT}

The enzyme NAMPT is highly conserved with orthologs in bacteria (94), invertebrate sponges (95), amphibians (96), birds and mammals (97). Not long after its discovery in 1994 by Samal et al. as a pre-B-cell colony enhancing factor (PBEF) secreted by activated lymphocytes and bone marrow stromal cells, Rongvaux et al. (98) showed that murine PBEF could catalyze the conversion of Nam to $\mathrm{NMN}$, a ratelimiting step in NAD biosynthesis. These authors also showed that Actinobacillus pleuropneumonia, a bacterium lacking the NadV gene, transformed with murine PBEF acquires NAD independence, confirming that the enzymatic activity is evolutionarily conserved from bacteria to mammals (98).

In recent years, NAMPT has received increasing attention due to new evidence indicating that it is a pleiotropic protein that may function as NBE, as well as growth factor, cytokine and adipokine [reviewed in $(18,25)]$. Although NAMPT lacks the typical signal peptide needed for extracellular secretion, the mature protein can be found in the medium of many cellular cultures due to an active secretion mechanism $(99,100)$. However, in conditions of cell damage eNAMPT can be released as passive diffusion across cell membranes, as usual for other DAMPS. In addition, the 3' untranslated region (UTR) contains multiple TATT motifs that are characteristic of cytokines (99).

The human NAMPT gene spans over $34.7 \mathrm{~kb}$ on the long arm of chromosome 7 (7q22) and contains 11 exons and 10 introns $(101,102)$. Two distinct promoter sites are present in the 5'-flanking region, suggesting the possibility of tissue specific differential expression (101). The region proximal to the promoter is GC-rich and contains 12 binding sites for specificity protein 1 (SP-1), multiple activating protein 2 (AP-2), lymphoid enhancer-binding factor 1 (LF-1), cAMP response elementbinding protein (CREB), and signal transducer and activator of transcription (STAT) binding sites $(101,103)$. Furthermore, the presence of two hypoxia inducible factor (HIF) response elements (HREs) suggest that the gene is upregulated under hypoxic conditions (104). The distal promoter region contains several CAAT boxes and TATA-like sequences, as well as binding sites for nuclear factor 1 (NF-1), nuclear factor kappa-lightchain-enhancer of activated B cells (NF-кB), CCAAT/enhancer binding protein $(\mathrm{C} / \mathrm{EBP} \beta)$, the glucocorticoid receptor (GR), and activating protein 1 (AP-1) (101). The majority of these transcription factors, including NF-1, AP-1, AP-2, NF- $\kappa$ B, and STAT, regulate cytokine expression and their presence in the promoter region of NAMPT suggests a role for this enzyme in immunity $(42,105)$.

Recently, $65 \mathrm{~kb}$ downstream of the NAMPT transcription start site on chromosome 7 (hg19: 105,856,018-105,860,658), a putative NAMPT enhancer was identified as specifically marked by H3K27ac and/or an accessible DNase I hypersensitive (DHS) signal (106). Fine-mapping of the 4.6-kb putative enhancer by stepwise $1-\mathrm{kb}$ deletions or insertions identified the $1-\mathrm{kb}$ enhancer " $B$ " region as responsible for (i) the control of expression of the NAMPT gene through c-MYC and MAX activities. (ii) In addition, it is the target of $\mathrm{H} 3 \mathrm{~K} 27$ acetylation; (iii) it regulates iNAD levels; and (iv) it is required for cell survival in NAMPTdependent tumors (106). Some genetic polymorphisms were identified in the human NAMPT gene, potentially responsible for NAMPT expression. Different representation of these Single Nucleotide Polymorphisms (SNPs) were described in patients with acute respiratory distress syndrome, type 2 diabetes, glucose and lipid metabolism alterations, diastolic blood pressure and hypertensive disorders compared to controls (107).

In the cell, NAMPT is abundant in the cytosol and present in the nucleus (108-110). Recently, Svoboda et al. showed that nuclear NAMPT translocation is a regulated process induced by genotoxic, oxidative, or dicarbonyl stress, mainly to finance NAD production for increased PARP and sirtuin activity (111). Moreover, NAMPT cytosol/nucleus localization changes according to cell cycle phases: it is excluded from the nucleus immediately after mitosis and it migrates back into it as the cell cycle progresses (111). These data were confirmed also by Grolla et al. that demonstrated a transport of NAMPT into the nucleus, GAPDH-mediated, in response to DNA damage (112). On the contrary, the presence of NAMPT in mitochondria remains controversial $(30,46,109)$.

Furthermore, an increasing number of cell types have been shown to release eNAMPT, including adipocytes, hepatocytes, cardiomyocytes, activated immune cells and several tumor cells (100, 113-117). While it was shown that a regulated positive secretory process exists (79), the exact mechanisms of release are presently under investigation. The most accredited hypothesis, yet to be confirmed in most cell types, is that eNAMPT is secreted through a "non-classical" secretory pathway, which is not blocked by monensin and brefeldin A, two inhibitors of the classical endoplasmatic reticulum (ER)-Golgi secretory pathway (79, 113, 118, 119). A recent paper showed that eNAMPT is carried in extracellular vesicles (EVs) through systemic circulation in mice and humans. EV-contained-eNAMPT is internalized into cells, enhancing NAD synthesis (120). The same conclusion was obtained by another group identifying that eNAMPT is actively secreted via exosomes from microglia during neuroinflammation due to ischemic injury (121). However, this mechanism of secretion could be context dependent: in fact in 3T3-L1 adipocytes eNAMPT release and secretion do not appear to occur through microvesicles (113).

Whether the extracellular form possesses specific differences in terms of truncations or post-translational modifications is presently unclear. Different groups suggested that deacetylation by sirtuins can impact eNAMPT secretion $(84,122)$, adding a new layer of complexity.

\section{NAPRT}

Highly conserved across species, the human NAPRT gene is located at chromosome 8q24.3, containing 12 exons. Similar to NAMPT, intracellular NAPRT is located in both the nucleus and the cytoplasm, but not detected in mitochondria $(46,71,123)$. 
Our group firstly reported the presence of an extracellular form of NAPRT in biological fluids in physiological (healthy donor's blood) and inflammatory conditions opening a new field of investigations (124).

Several information about NAPRT expression and regulation emerged in tumors, in relation to the efficacy of NAMPT inhibitors (NAMPTi) as potential anti-cancer agents $(125,126)$, as described in the dedicated section NAMPT and NAPRT in Tumors.

\section{EXTRACELLULAR NAMPT AND NAPRT: ADIPOCYTOKINES AND DAMPS}

In addition to a direct effect on NAD and its metabolites, the enzymes involved in synthesis of NAD also have important extracellular functions, as summarized in Figure 3.

\section{eNAMPT Functions}

eNAMPT/PBEF was first identified as an immunomodulatory cytokine able to synergize with interleukin 7 (IL-7) and stem cell factor (SCF) to promote pre-B cell colony formation (99). It is now well-established that eNAMPT is a soluble factor that is up-regulated upon activation in innate and adaptive immune cells, including neutrophils, monocytes, and macrophages, and in epithelial and endothelial cells $(18,127)$. NAMPT expression can be rapidly induced by inflammatory signals, in particular both pathogen-derived lipopolysaccharide (LPS) and host-derived inflammatory stimuli (TNF- $\alpha$, IL-1 $\beta$, IL-6, leptin) in amniotic epithelial cells, macrophages, human osteoarthritic chondrocytes and a synovial fibroblast cell line (101, 103, 128, 129).

eNAMPT has a variety of biological functions (Figure 3): (i) it is an important mediator of inflammatory programs $(18,130)$ and (ii) it acts as a cytokine that modulates the

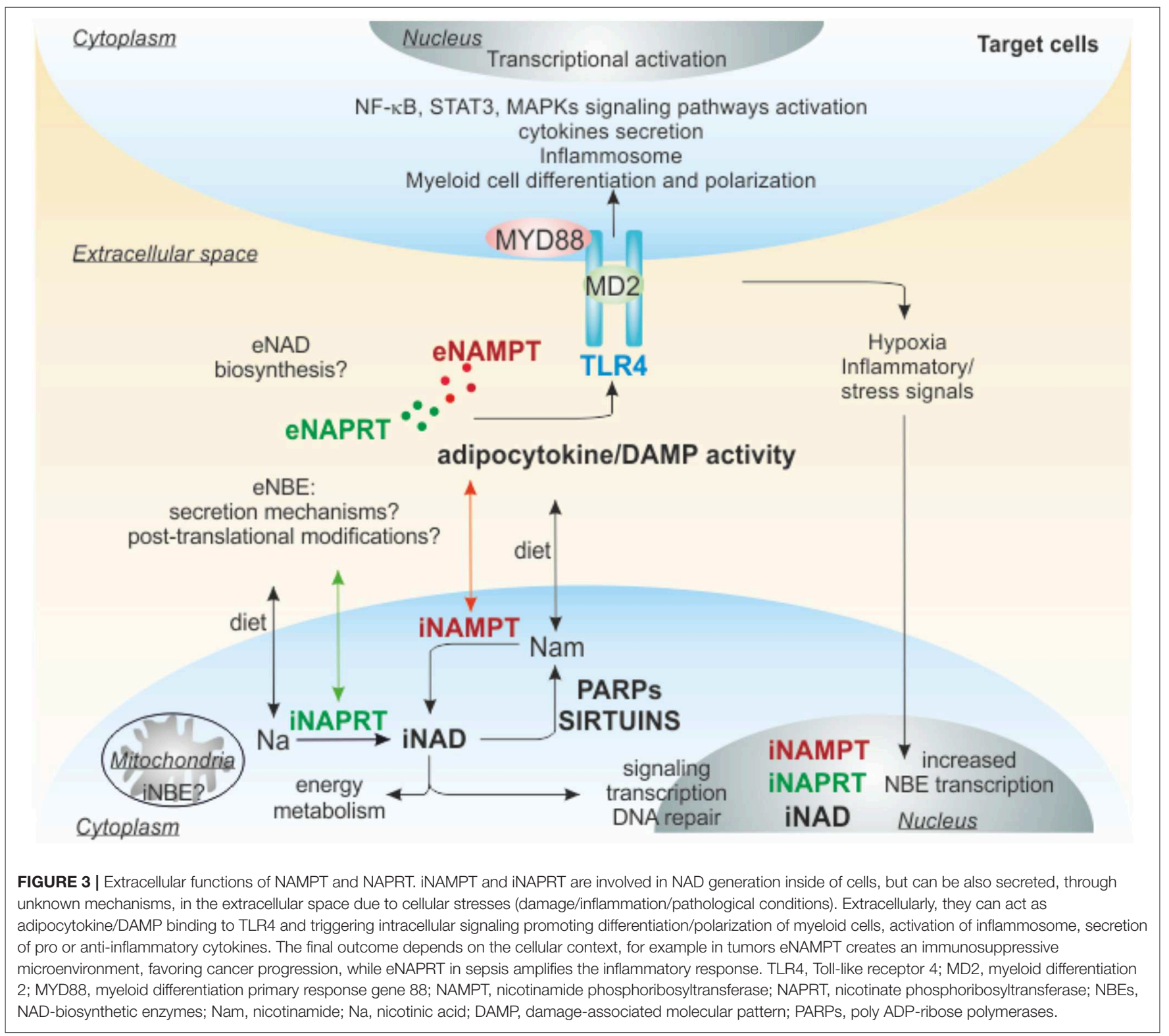


immune response (42). Notably, the cytokine-like functions appear, at least in part, independent of the protein catalytic activity, as inferred by the use of an enzymatically inactive NAMPT H247E mutant that retains the ability to activate signaling pathways $(26,83,131,132)$. In keeping with this view, NAMPT's substrates PRPP and ATP are apparently unavailable extracellularly to sustain its enzymatic activity (56). Following NAMPT treatment, interleukins IL-1 $\beta$, IL-6, IL-10, and tumor necrosis factor- $\alpha$ (TNF- $\alpha$ ) are up-regulated and secreted by peripheral blood mononuclear cells (PBMCs) and CD14 ${ }^{+}$ monocytes (133). Co-stimulatory molecules such as CD40, CD54, and CD80 are also up-regulated in response to eNAMPT exposure, an effect mediated through the activation of PI3-kinase and MAPKs pathways (133). Furthermore, in macrophages NAMPT increases matrix metalloproteinases (MMPs) expression and activity (134). In addition, (iii) eNAMPT has anti-apoptotic effects on immune cells, including neutrophils and macrophages, for example it promotes macrophage survival after induction of endoplasmic reticulum (ER) stress triggering IL-6 secretion and phosphorylation of STAT3 (103). (iv) eNAMPT is also reported as an adipokine, also known as visfatin, playing a critical role in the regulation of glucose-stimulated insulin secretion in pancreatic $\beta$ cells $(21,135)$. While a direct role for insulin receptor in eNAMPT-mediated cytokine release was discarded $(18,133)$, eNAMPT is up-regulated in obese and diabetic patients: it is enriched in visceral fat and secreted by adipocytes $(113,136,137)$. The role as adipokine seems more related to the extracellular generation of NMN: in fact systemic administration of NMN to aged mice or mice subjected to a high-fat diet restores normal NAD levels in white adipose tissue and liver, and ameliorates glucose intolerance and type II diabetic syndrome (138). (v) eNAMPT can also act as a pro-angiogenic factor, promoting endothelial cell proliferation, migration, and capillary tube formation in a concentrationdependent manner in human umbilical vein endothelial cells (HUVEC) (139-142). These proliferative effects of eNAMPT seem to be mediated, or at least partially mediated by vascular endothelial cell growth factor (VEGF), the master regulator of endothelial cell program (139). Thus, eNAMPT upregulates VEGF synthesis and secretion, as well as the expression of the VEGF receptor 2, which has been proposed to mediate the angiogenic actions of VEGF (139). Beside VEGF, in endothelial cells eNAMPT upregulates production of other pro-angiogenic soluble factors, such as fibroblast growth factor-2 (FGF-2), monocyte chemoattractant protein-1 (MCP-1) and IL-6 (143, 144). Indeed, both MCP-1 and FGF-2 have also been identified as mediators of eNAMPT-induced angiogenesis (143). Beyond in vitro studies, the angiogenic activities of eNAMPT were demonstrated in ex vivo and in vivo approaches $(139,140)$.

\section{eNAPRT Functions}

Starting from the structural and functional similarity between human NAMPT and NAPRT (91), our group for the first time investigated whether NAPRT exists in an extracellular form, thus sharing with NAMPT its moonlighting abilities (124). By setting up a new luminex/ELISA assay, we dosed eNAPRT in a cohort of $>100$ plasma from normal blood donors (HD), highlighting a mean concentration similar to that recorded for eNAMPT (in the range of $1.5-2.0 \mathrm{ng} / \mathrm{ml}$ ), with no differences according to gender or age. We used mass spectrometry to confirm the presence of NAPRT peptides in human plasma. Moreover, we demonstrated that endogenous eNAPRT is enzymatically active $(86,124)$. Analyzing eNAPRT in sera from patients with acute or chronic inflammatory conditions, we demonstrated that this enzyme strongly increased in acute inflammatory diseases such as sepsis and septic shock, driving inflammatory responses related to the activation of macrophages (Figure 3). We also observed that cellular stress [i.e., treatment with TNF- $\alpha$ and cycloheximide to trigger apoptosis, or with ionomycin and carbonyl cyanide 3-chlorophenylhydrazone (CCCP) to trigger necrosis] is accompanied by marked increase of eNAPRT in macrophage culture media (124), as previously described also for HMGB-1 (9) and others DAMPs (145).

\section{eNAMPT/eNAPRT in Myeloid Cells Function: the Role of TLR4}

NAD synthesis has a driving role in myeloid differentiation and in supporting macrophage inflammatory responses $(42,146$, 147), prompting investigation on the function of NAMPT and NAPRT in these cells.

Increasing evidence demonstrated a direct role of NAMPT in regulating the differentiation program and the metabolic phenotypes of myeloid cells. Both iNAMPT and eNAMPT influence monocyte/macrophages differentiation, polarization and migration $(132,146,148)$. We described a role for eNAMPT in creating an immunosuppressive and tumorpromoting microenvironment in chronic lymphocytic leukemia, where eNAMPT is important for the differentiation of monocytes toward tumor-supporting M2 macrophages (132). Recently, it was demonstrated that iNAMPT acts also on myeloid-derived suppressor cells (MDSCs), where NAMPT blocks CXCR4 transcription, via a SIRT1/HIF-1 $\alpha$ axis. The activation of this circuit, in turn, leads to MDSCs mobilization and enhances the production of nitric oxide, promoting immunosuppression (149).

The NAMPT/NAD/SIRT1 axis seems to play a relevant role in myeloid cell activation. NAMPT-dependent NAD generation is crucial in the metabolic switch characterizing the transition from the early stage of acute inflammation, primarily relies on glycolysis, to the later adaptation phase more dependent on fatty acid oxidation (FAO) for energy production (150-152). Moreover, NAMPT/NAD levels significantly increased during activation of pro-inflammatory M1 macrophages (153). In a further feedback loop some cytokines, including IL-6 and TNF- $\alpha$, induced during monocyte activation, are able to promote NAMPT expression via HIF- $1 \alpha$. In turn, NAMPT, triggering NF-kB signaling pathway, sustains IL6 and TNFA transcription forcing myeloid cell activation (131). It has been also shown that NAMPT/NAD/SIRT1 axis can regulate neutrophilic granulocyte differentiation via CCAAT/enhancer-binding protein $\alpha / \beta$ $(\mathrm{C} / \mathrm{EBP} \alpha / \beta)$ induction, ultimately, up-regulating granulocyte colony-stimulating factor (G-CSF). In turn, G-CSF further increases NAMPT levels (148). NAMPT inhibition, reducing 
NAD levels, thereby decreasing SIRT1 activity, leads to the dramatic elevation of acetylated $\mathrm{C} / \mathrm{EBP} \alpha$ levels and reduces amounts of total $\mathrm{C} / \mathrm{EBP} \alpha$ protein, accompanied by diminished mRNA expression of C/EBP $\alpha$ target genes (G-CSF, G-CSFR, and ELANE) $(148,154)$. Moreover, exposure of the acute myeloid leukemia cell line HL-60 to recombinant NAMPT or NAMPT overexpression induced myeloid differentiation of these cells perse (154).

A controversial issue in NAMPT biology is whether its cytokine-like properties are all linked to its enzymatic activity or are mediated by the binding to a cell surface receptor. In 2015, Camp et al. showed that eNAMPT produces robust TLR4mediated NF-kB signaling activation, by directly binding TLR4MD2 (26) (Figure 3). However, due to possible contamination of LPS, the natural ligand of TLR4, in the recombinant NAMPT preparations used to treat cells in vitro, the interpretation of these results remains controversial. Our group recently confirmed the binding of eNAMPT to TLR4 in macrophage cellular model (124), performing surface plasmon resonance (SPR) under the same conditions previously established for the NAMPT-TLR4 interaction (26). More recently, the same group that firstly identified TLR4 as NAMPT receptor published new details about this interaction (155). At the same time, a direct role of NAD in activating the inflammasome was recently reported by Yang et al. The authors demonstrated that NAD manipulation, using NAMPT inhibitors or the treatment with NAD precursors, affects TLR4-mediated NF- $\kappa$ B activation and PYD-domain 3 (NLRP3) inflammasome activity connecting intracellular NAD levels and inflammation (156).

Similar properties were attributed to eNAPRT. By using a surface coated with an anti-NAPRT antibody, we showed that a pre-mixed solution of recombinant ( $r$ )NAPRT and rTLR4 resulted in increased binding when compared to rNAPRT alone, indicating that a direct molecular interaction was occurring between the proteins (124). TLR4 triggering by rNAPRT activates an inflammatory signature in human macrophages differentiated from PBMC of healthy donors, as observed also using rNAMPT, promoting robust activation of NF- $\kappa \mathrm{B}$ signaling, transcription and secretion of proinflammatory cytokines, including IL- $1 \beta$, IL-8, TNF- $\alpha$, CCL3, and inflammatory mediators such as caspase-1 (CASP1) and P2X purinoreceptor (124) (Figure 3). These effects are lost in TLR4-silenced macrophages. Accordingly, in macrophages, derived from TLR4 ${ }^{-/}$mice, rNAPRT exposure was not able to activate NF- $\kappa \mathrm{B}$ signaling and cytokine production. Lastly, we demonstrated that the rNAPRT enzymatic deficient mutant is still able to trigger inflammosome in macrophages, indicating that the enzymatic activity is irrelevant to the pro-inflammatory functions of eNAPRT.

rNAPRT, as previously observed for eNAMPT $(132,146,148)$, is also able to force monocyte differentiation into macrophages, up-regulating macrophage colony-stimulating factor (M-CFS). This function in triggering macrophage differentiation is a unique feature of eNAMPT/eNAPRT and not shared by LPS, suggesting that even though TLR4 is a receptor for multiple soluble factors and proteins, each specific ligand has a peculiar role. Notably, eNAPRT could be detected in macrophage culture supernatants, suggesting that macrophages are a source of eNAPRT in vivo.

Lastly, in this paper, we demonstrated that the signaling functions of hNAMPT and hNAPRT are not an evolutionarily conserved trait. In fact, the bacterial rNAPRT (PncB) or the bacterial rNAMPT (NadV) invariably failed to activate NF$\kappa \mathrm{B}$ signaling in macrophages. Furthermore, a comparison of the surface properties of the bacterial and hNAPRT proteins revealed the presence in hNAPRT of an arginine-rich stretch (65 RFLRAFRLR) forming a large mouth-like positively charged area on the top of the dimer, which is absent in the bacterial ortholog, but is present in a similar form in NAMPT, and could be involved in the binding to TLR4 (124). Even if several issues remain to be investigated, these data support the notion of another NBE acting as extracellular mediator with a direct role in macrophage functions, binding TLR4.

\section{NAMPT AND NAPRT AS BIOMARKERS OF CHRONIC AND ACUTE INFLAMMATORY DISEASES}

iNAMPT over-expression as well as increased circulating levels of eNAMPT were documented in metabolic/inflammatory conditions including obesity, type 2 diabetes, metabolic syndromes, atherogenic inflammatory diseases, therefore supporting a role for eNAMPT as a potential biomarker of cardio- cerebro-vascular disorders (157-160). Enhanced eNAMPT levels are also described in kidney transplantation recipients (161), polycystic ovary syndrome (162), preeclampsia (163), and acute coronary syndrome (158, 164). Increased eNAMPT levels were additionally reported in non-metabolic chronic inflammatory diseases [i.e., osteoarthritis (103) and acute lung injury (ALI) $(165,166)]$, characterized by systemic inflammation. eNAMPT also seems to play a role in several types of infections like sepsis $(167,168)$ or intrauterine infection (chorioamnionitis) (169), and in autoimmune inflammatory diseases including psoriasis (170), rheumatoid arthritis (RA) (171) Crohn's disease (CD) and ulcerative colitis (UC) (172). Table 1 summarized main activities of $\mathrm{i} / \mathrm{eNAMPT}$ in these pathological conditions.

The first indication that NAPRT can be present in the extracellular space was published by our group in 2019. We dosed eNAPRT in sera from patients with sepsis or septic shock due to bacterial infections. Our results indicated that median eNAPRT levels picked-up to $\sim 25 \mathrm{ng} / \mathrm{ml}$ in septic individuals (compared to a median of about $2 \mathrm{ng} / \mathrm{ml}$ in $\mathrm{HD}$ ), underlying high levels of this enzyme in this acute inflammatory condition (124). Circulating NAPRT has a role in mediating endotoxin tolerance at low/physiological doses, in fact the highest plasmatic eNAPRT levels were dosed in patients who died because of septic shock, while those with low concentrations survived. We confirmed a significant association between high levels of eNAPRT and mortality, suggesting that eNAPRT is a novel risk factor in sepsis (124). Even if the biological explanation behind this observation is still partly missing, findings in our work are significant starting points to evaluate the functional 
TABLE 1 | NAMPT and NAPRT functions in chronic and acute inflammatory diseases.

\begin{tabular}{|c|c|c|c|}
\hline Type of disease & Main findings & Therapeutic options & References \\
\hline \multicolumn{4}{|l|}{ e/iNAMPT } \\
\hline Type 2 diabetes & $\begin{array}{l}\text {-Higher eNAMPT levels in cases than controls } \\
\text {-eNAMPT induces a diabetic phenotype in } \\
\text { pancreatic islets }\end{array}$ & Blocking Ab? & $(157,173)$ \\
\hline Obesity & $\begin{array}{l}\text {-Higher eNAMPT levels in cases than controls } \\
\text {-iNAMPT supports adipose plasticity and the } \\
\text { pathological progression to obesity. }\end{array}$ & $\begin{array}{l}\text { Blocking Ab? } \\
\text { Pharmacological inhibitors? }\end{array}$ & $(157,174)$ \\
\hline $\begin{array}{l}\text { Atherogenic inflammatory } \\
\text { diseases; cardio- cerebro- } \\
\text { vascular disorders; stroke; } \\
\text { acute coronary syndrome }\end{array}$ & $\begin{array}{l}\text {-eNAMPT prognostic marker of atherosclerosis, } \\
\text { endothelial dysfunction, and vascular damage } \\
\text {-Active player promoting vascular inflammation } \\
\text {-Deregulated NAD metabolism }\end{array}$ & $\begin{array}{l}\text { Blocking Ab? } \\
\text { Pharmacological inhibitors (pre-clinical) }\end{array}$ & $(158-160,164,175)$ \\
\hline Kidney transplant recipients & $\begin{array}{l}\text {-eNAMPT was significantly higher in kidney allograft } \\
\text { recipients than in HD } \\
\text {-Associated with endothelial damage }\end{array}$ & Blocking Ab? & $(161)$ \\
\hline $\begin{array}{l}\text { Polycystic ovary syndrome; } \\
\text { preeclampsia }\end{array}$ & $\begin{array}{l}\text {-Higher eNAMPT levels in cases than controls } \\
\text { - eNAMPT induces the expression of pro- } \\
\text { angiogenic factors }\end{array}$ & Blocking Ab? & $(162,163)$ \\
\hline $\begin{array}{l}\text { Acute lung injury (ALI); acute } \\
\text { respiratory distress syndrome } \\
\text { (ARDS) }\end{array}$ & $\begin{array}{l}\text {-Higher eNAMPT levels in cases than controls } \\
\text {-eNAMPT induces the secretion of inflammatory } \\
\text { cytokines and activation } \\
\text { of signaling pathways } \\
\text {-iNAMPT supports NAD metabolism, } \\
\text { inhibiting apoptosis }\end{array}$ & $\begin{array}{l}\text { Blocking Ab (pre-clinical) } \\
\text { Pharmacological inhibitors (pre-clinical) }\end{array}$ & $(165,166)$ \\
\hline Sepsis; septic shock & $\begin{array}{l}\text {-Higher eNAMPT levels in cases than controls } \\
\text {-eNAMPT induces the secretion of inflammatory } \\
\text { cytokines and activation } \\
\text { of signaling pathways, } \\
\text { supporting inflammation } \\
\text {-Diagnostic and prognostic biomarkers (risk factor) }\end{array}$ & Blocking Ab? & $(167,168)$ \\
\hline $\begin{array}{l}\text { Intrauterine infection } \\
\text { (chorioamnionitis) }\end{array}$ & -Higher eNAMPT levels in cases than controls & Blocking Ab? & $(163,169)$ \\
\hline Psoriasis & $\begin{array}{l}\text {-Higher eNAMPT levels in cases than controls } \\
\text {-Positive correlation with disease severity }\end{array}$ & Blocking Ab? & $(170)$ \\
\hline $\begin{array}{l}\text { Rheumatoid arthritis (RA); } \\
\text { osteoarthritis }\end{array}$ & $\begin{array}{l}\text {-Higher eNAMPT levels in cases than controls } \\
\text {-eNAMPT induces the secretion of inflammatory } \\
\text { cytokines and activation } \\
\text { of signaling pathways } \\
\text {-Block NAMPT have reduced RA progression } \\
\text { and inflammatory markers }\end{array}$ & $\begin{array}{l}\text { Blocking Ab? } \\
\text { Pharmacological inhibitors (pre-clinical) }\end{array}$ & $(103,171,176)$ \\
\hline $\begin{array}{l}\text { Inflammatory bowel disease } \\
\text { (IBD); Crohn's disease (CD); } \\
\text { and ulcerative colitis (UC) }\end{array}$ & $\begin{array}{l}\text {-iNAMPT/eNAMPT overexpression/secretion } \\
\text {-Association with inflammation, hypoxia (active) and } \\
\text { tissue repair (inactive disease) }\end{array}$ & $\begin{array}{l}\text { Blocking Ab? } \\
\text { Pharmacological inhibitors (pre-clinical) }\end{array}$ & $(172,177)$ \\
\hline $\begin{array}{l}\text { Solid tumors: colorectal, ovarian, } \\
\text { breast, gastric, prostate, thyroid, } \\
\text { pancreatic cancers, melanoma, } \\
\text { gliomas, sarcoma, endometrial } \\
\text { =carcinomas, and hematological } \\
\text { malignancies }\end{array}$ & $\begin{array}{l}\text {-iNAMPT/eNAMPT over expression } \\
\text {-Negative prognostic marker - Regulates metabolic } \\
\text { adaptation, DNA repair, gene expression, signaling } \\
\text { pathways, cell growth, invasion, stemness, epithelial } \\
\text { to mesenchymal transition program, } \\
\text { metastatization, angiogenesis, secretion of both } \\
\text { pro-inflammatory and immunosuppressive } \\
\text { cytokines, resistance to genotoxic stress }\end{array}$ & $\begin{array}{l}\text { Blocking Ab (pre-clinical) } \\
\text { Pharmacological inhibitors (pre-clinical and } \\
\text { phase I-II-III) }\end{array}$ & $(18,25,106,178,179)$ \\
\hline \multicolumn{4}{|l|}{ e/iNAPRT } \\
\hline Sepsis/septic shock & $\begin{array}{l}\text {-Higher eNAPRT levels in cases than controls } \\
\text {-eNAPRT activates inflammosome } \\
\text {-Risk factor for patient survival }\end{array}$ & Blocking Ab? & $(124)$ \\
\hline $\begin{array}{l}\text { Prostate, ovarian, colorectal, } \\
\text { and pancreatic cancers }\end{array}$ & $\begin{array}{l}\text {-NAPRT gene amplification -iNAPRT } \\
\text { overexpression; -correlation with a BRCAness gene } \\
\text { expression signature } \\
\text {-NAPRT silencing reduced energy status, protein } \\
\text { synthesis, and cell size }\end{array}$ & Pharmacological inhibitors (pre-clinical) & $(88,106,123,180)$ \\
\hline
\end{tabular}

$H D$, healthy donors; $A b$, antibody. 
role of eNAPRT as DAMP in sepsis, but also in others acute inflammatory conditions (Table 1).

\section{NAMPT and NAPRT in Tumors}

In tumors increased i/eNAMPT have been reported, not only as biomarkers, but also as drivers of tumor progression $(18,25,178)$, detailed in Table 1 . Cancer cells require high energetic needs to support their proliferation. Increased demand of NAD, obtained through NAMPT overexpression, is needed to finance cellular metabolism and NAD-consuming reactions, including DNA repair activity (41). NAMPT is overexpressed in a broad range of solid tumors including colorectal, ovarian, breast, gastric, prostate, thyroid, pancreatic cancers, melanoma, gliomas, sarcoma, endometrial carcinomas, and hematological malignancies, as reviewed in Dalamaga et al. (178), Yaku et al. (179), Audrito et al. (25), and Chowdhry et al. (106). NAMPT, as intracellular and extracellular factor, exerts a direct role on tumor cells increasing tumor aggressiveness, correlating with worse prognosis and regulating different processes including metabolic adaptation, DNA repair, gene expression, signaling pathways, cell growth, invasion, stemness, epithelial to mesenchymal transition program, metastatization, angiogenesis, secretion of both proinflammatory and immunosuppressive cytokines, resistance to genotoxic stress, as reviewed in Dalamaga et al. (178) and Audrito et al. (25). Very recently, Nacarelli et al. described also a role of NAMPT in governing the strength of the proinflammatory senescence-associated secretory (SASP) phenotype observed during senescence, a process implicated in tissue aging and cancer (181).

Recently, amplification of NAPRT gene was detected in prostate, ovarian, and pancreatic cancers $(106,123)$. NAPRT gene amplification in tumors correlated with NAPRT expression in matched normal tissues, suggesting a role for tissue context in determining which cancers amplify NAPRT (106). DuartePereira et al. in 2016 extensively studied expression of NAMPT and NAPRT in different tumor types and normal tissues (88). The initial step in that study was to evaluate NAPRT and NAMPT expression in a set of normal human tissues, highlighting a widespread expression for both genes. In tumors, while NAMPT was expressed at mRNA and protein levels in all samples analyzed, NAPRT protein levels were highly diverse, being undetected in several cases. Likewise, NAPRT protein is differentially expressed between cell lines, with markedly decreased expression in carcinoma cell lines MKN28 (gastric), 786-O (renal), HCT116 (colorectal), and in all leukemia cell lines tested (HL-60, NB4, and ML2) (88). Another paper highlighted a role for NAPRT, together with NAMPT, as negative prognostic marker in colorectal cancer, based on TCGA RNAsequencing data and protein tissue array (180). In a recent work the overexpression of NAPRT in ovarian cancer, correlated with a BRCAness gene expression signature. In this context, NAPRT silencing reduced energy status, protein synthesis, and cell size (123). These results suggest that both transcriptional and post-transcriptional mechanisms regulate the expression of the NAPRT gene in cancer types, including mutations in transcription factor binding sites of CREB and Sp1, to promoter methylation and alternative splicing (88). Epigenetic silencing of
NAPRT, driven by the hypermethylation of $\mathrm{CpG}$ islands activity of mutant Protein Phosphatase $\mathrm{Mg}^{2+/} \mathrm{Mn}^{2+}$ Dependent 1D (PPM1D), also known as Wip1, is a recently defined mechanism. As a consequence, PPM1D mutated tumors are particularly sensitive to NAMPTi (182). It was shown that the lack of NAPRT expression in some tumors, such as neuroblastoma, glioblastoma (183) or lymphomas (184), puts NAPRT as a biomarker for the use of $\mathrm{Na}$ as a chemoprotectant agent during treatment with NAMPT inhibitors (126). In NAPRT-negative tumors, NAMPT inhibition provides a novel synthetic lethal therapeutic strategy by inducing metabolic stress, while normal cells are rescued by Na via activation of the NAPRT pathway (123, 183-185).

We demonstrated the presence of eNAPRT in sera from patients with a diagnosis of cancer, including solid tumors (prostate, lung and bladder cancer, mesothelioma and metastatic melanoma) and hematological malignancies [myeloma, chronic lymphocytic leukemia (CLL), and diffuse large cell lymphoma (DLCL)] (124) as summarized in Table 1. The median value of circulating eNAPRT is double compared to HD, suggesting a possible role of this enzyme in tumor microenvironment.

Several issues remain to be addressed. First and foremost, it will be important to understand the relationship between eNAPRT and eNAMPT: our findings suggest that they have multiple roles in acute vs. chronic inflammation, engaging TLR4 in different pathological conditions (Table 1) and alerting the immune system to distinct sets of "dangers."

\section{IMPLICATIONS FOR THERAPY AND CONCLUDING REMARKS}

NAMPT inhibitors were primarily developed as anticancer agents, depleting NAD and causing metabolic crash and tumor cell death (Table $\mathbf{1}$ ).

For iNAMPT selective pharmacological inhibitors exist, the best studied being FK866 (also known as APO866) and GMX1778 (also known as CHS-828), among others (25, 178, 186-189). These inhibitors have been studied in cancer cell lines and animal models showing cytotoxicity and tumor regression $(178,190)$. Despite these important results in vitro and in vivo, phase I clinical trials in advanced solid tumors and leukemia showed no objective tumor remission and toxicity $(191,192)$. One of the known mechanism leading to the partial failure of NAMPTi treatment is due to the concomitant expression of NAPRT $(88,106,123,125,126,184)$, that can overcome NAMPT inhibition. A complete analysis of expression of these two NBE in tumors should be made to design better therapeutic strategies that deplete NAD improving efficacy. Development of novel NAPRTi, to obtain complete depletion of NAD in tumor insensitive to NAMPTi due to the overexpression of NAPRT should also be considered. Previous studies indicated the ability of structural analogs of Na to inhibit NAPRT enzymatic activity $(85,89)$. Among this class of compound, 2-hydroxinicotinic acid (2-HNA) is the most promising, showing significant inhibition of NAPRT enzymatic activity and function in ovarian cancer in vitro and in xenograft models (123). The use of NAPRT inhibitors 
appears as a promising strategy to overcome NAPRT-mediated resistance to NAMPT inhibitors in patients (Table $\mathbf{1}$ ).

Blocking the extracellular cytokine-like function of eNAMPT and eNAPRT would be very useful to restore immune competence in cancer, as well as, infection setting (Table 1). In the tumor microenvironment, neutralization of eNAMPT using blocking antibodies could be effective to repolarize myeloid cells (TAMs/MDSCs) against tumor. Some groups/companies are working on the production of these antibodies (193), hypothesizing a combination strategy with immunotherapy, or a double inhibition of i/eNAMPT. Blocking eNAPRT in acute inflammatory conditions, such as in septic patients, could be an important strategy to prevent the damaging action of a massive secretion of eNAPRT leading to decreased survival of patients, but this remains, at this moment, only a speculative hypothesis.

In conclusion, in this review we summarized current knowledge on these two old enzymes involved in NAD biosynthesis that can powerfully modulate immune responses. If NAMPT has now an acknowledged role in regulating several cellular processes in physiological and pathological conditions,

\section{REFERENCES}

1. Broz P, Monack DM. Newly described pattern recognition receptors team up against intracellular pathogens. Nat Rev Immunol. (2013) 13:55165. doi: $10.1038 /$ nri3479

2. Cao X. Self-regulation and cross-regulation of pattern-recognition receptor signalling in health and disease. Nat Rev Immunol. (2016) 16:3550. doi: 10.1038/nri.2015.8

3. Takeuchi O, Akira S. Pattern recognition receptors and inflammation. Cell. (2010) 140:805-20. doi: 10.1016/j.cell.2010.01.022

4. Gong T, Liu L, Jiang W, Zhou R. DAMP-sensing receptors in sterile inflammation and inflammatory diseases. Nat Rev Immunol. (2019) 20:95112. doi: 10.1038/s41577-019-0215-7

5. Shi Y, Evans JE, Rock KL. Molecular identification of a danger signal that alerts the immune system to dying cells. Nature. (2003) 425:51621. doi: 10.1038/nature01991

6. Bianchi ME. DAMPs, PAMPs and alarmins: all we need to know about danger. J Leukoc Biol. (2007) 81:1-5. doi: 10.1189/jlb.0306164

7. Chen GY, Nunez G. Sterile inflammation: sensing and reacting to damage. Nat Rev Immunol. (2010) 10:826-37. doi: 10.1038/nri2873

8. Pradeu T, Cooper EL. The danger theory: 20 years later. Front Immunol. (2012) 3:287. doi: 10.3389/fimmu.2012.00287

9. Scaffidi P, Misteli T, Bianchi ME. Release of chromatin protein HMGB1 by necrotic cells triggers inflammation. Nature. (2002) 418:191-195. doi: 10.1038/nature00858

10. Bianchi ME, Crippa MP, Manfredi AA, Mezzapelle R, Rovere Querini P, Venereau E. High-mobility group box 1 protein orchestrates responses to tissue damage via inflammation, innate and adaptive immunity, and tissue repair. Immunol Rev. (2017) 280:74-82. doi: 10.1111/ imr.12601

11. Yang H, Ochani M, Li J, Qiang X, Tanovic M, Harris HE, et al. Reversing established sepsis with antagonists of endogenous high-mobility group box 1 . Proc Natl Acad Sci USA. (2004) 101:296-301. doi: 10.1073/pnas.2434651100

12. Andersson U, Tracey KJ. HMGB1 is a therapeutic target for sterile inflammation and infection. Annu Rev Immunol. (2011) 29:139-62. doi: 10.1146/annurev-immunol-030409-101323

13. Wang H, Bloom O, Zhang M, Vishnubhakat JM, Ombrellino M, Che J, et al. HMG-1 as a late mediator of endotoxin lethality in mice. Science. (1999) 285:248-51. doi: 10.1126/science.285.5425.248

14. Yatim N, Cullen S, Albert ML. Dying cells actively regulate adaptive immune responses. Nat Rev Immunol. (2017) 17:262-75. doi: 10.1038/nri.2017.9 and as biomarker in several diseases, the biology of NAPRT, especially as new soluble factor, acting as DAMP in acute inflammation, needs to be extensively studied to determine potential pharmacological settings.

\section{AUTHOR CONTRIBUTIONS}

VA and SD have made a substantial, direct and intellectual contribution to the work, contributed equally to writing the manuscript, and approved it for publication. VM contributed to writing the final version of the manuscript and approved it for publication.

\section{FUNDING}

This work was supported by Gilead Fellowship program 2018, by the Ministry of Education University and Research-MIUR, PRIN Project 2017CBNCYT and Progetto strategico di Eccellenza Dipartimentale \#D15D18000410001 (the latter awarded to the Dept. of Medical Sciences, University of Turin) and ITN INTEGRATA program (grant agreement 813284).

15. Corriden R, Insel PA. Basal release of ATP: an autocrineparacrine mechanism for cell regulation. Sci Signal. (2010) 3:re1. doi: 10.1126/scisignal.3104re1

16. Junger WG. Immune cell regulation by autocrine purinergic signalling. Nat Rev Immunol. (2011) 11:201-12. doi: 10.1038/nri2938

17. Di Virgilio F, Sarti AC, Falzoni S, De Marchi E, Adinolfi E. Extracellular ATP and P2 purinergic signalling in the tumour microenvironment. Nat Rev Cancer. (2018) 18:601-18. doi: 10.1038/s41568-018-0037-0

18. Garten A, Schuster S, Penke M, Gorski T, de Giorgis T, Kiess W. Physiological and pathophysiological roles of NAMPT and NAD metabolism. Nat Rev Endocrinol. (2015) 11:535-46. doi: 10.1038/nrendo.2015.117

19. Verdin $\mathrm{E} . \mathrm{NAD}(+)$ in aging, metabolism, and neurodegeneration. Science. (2015) 350:1208-13. doi: 10.1126/science.aac4854

20. Tanaka T, Nabeshima Y. Nampt/PBEF/Visfatin: a new player in beta cell physiology and in metabolic diseases? Cell Metab. (2007) 6:3413. doi: 10.1016/j.cmet.2007.10.004

21. Imai S. Nicotinamide phosphoribosyltransferase (Nampt): a link between NAD biology, metabolism, and diseases. Curr Pharm Des. (2009) 15:208. doi: 10.2174/138161209787185814

22. Dahl TB, Holm S, Aukrust P, Halvorsen B. Visfatin/NAMPT: a multifaceted molecule with diverse roles in physiology and pathophysiology. Annu Rev Nutr. (2012) 32:229-43. doi: 10.1146/annurev-nutr-071811-150746

23. Jieyu H, Chao T, Mengjun L, Shalong W, Xiaomei G, Jianfeng L, et al. Nampt/Visfatin/PBEF: a functionally multi-faceted protein with a pivotal role in malignant tumors. Curr Pharm Des. (2012) 18:612332. doi: 10.2174/138161212803582531

24. Carbone F, Liberale L, Bonaventura A, Vecchie A, Casula $\mathrm{M}$, Cea $\mathrm{M}$, et al. Regulation and function of extracellular nicotinamide phosphoribosyltransferase/visfatin. Compr Physiol. (2017) 7:603-21. doi: 10.1002/cphy.c160029

25. Audrito V, Manago A, Gaudino F, Deaglio S. Targeting metabolic reprogramming in metastatic melanoma: the key role of nicotinamide phosphoribosyltransferase (NAMPT). Semin Cell Dev Biol. (2019) 98:192201. doi: 10.1016/j.semcdb.2019.05.001

26. Camp SM, Ceco E, Evenoski CL, Danilov SM, Zhou T, Chiang ET, et al. Unique toll-like receptor 4 activation by NAMPT/PBEF induces NFkappaB signaling and inflammatory lung injury. Sci Rep. (2015) 5:13135. doi: 10.1038/srep13135

27. Houtkooper RH, Canto C, Wanders RJ, Auwerx J. The secret life of NAD+: an old metabolite controlling new metabolic signaling pathways. Endocr Rev. (2010) 31:194-223. doi: 10.1210/er.2009-0026 
28. Dolle C, Skoge RH, Vanlinden MR, Ziegler M. NAD biosynthesis in humansenzymes, metabolites and therapeutic aspects. Curr Top Med Chem. (2013) 13:2907-17. doi: 10.2174/15680266113136660206

29. Ruggieri S, Orsomando G, Sorci L, Raffaelli N. Regulation of NAD biosynthetic enzymes modulates NAD-sensing processes to shape mammalian cell physiology under varying biological cues. Biochim Biophys Acta. (2015) 1854:1138-49. doi: 10.1016/j.bbapap.2015.02.021

30. Yang H, Yang T, Baur JA, Perez E, Matsui T, Carmona JJ, et al. Nutrientsensitive mitochondrial NAD+ levels dictate cell survival. Cell. (2007) 130:1095-107. doi: 10.1016/j.cell.2007.07.035

31. Yaku K, Okabe K, Nakagawa T. NAD metabolism: implications in aging and longevity. Ageing Res Rev. (2018) 47:1-7. doi: 10.1016/j.arr.2018.05.006

32. Allison SJ, Knight JR, Granchi C, Rani R, Minutolo F, Milner J, et al. Identification of LDH-A as a therapeutic target for cancer cell killing via (i) p53/NAD(H)-dependent and (ii) p53-independent pathways. Oncogenesis. (2014) 3:e102. doi: 10.1038/oncsis.2014.16

33. Yang $\mathrm{Y}$, Sauve $\mathrm{AA}$. $\mathrm{NAD}(+)$ metabolism: bioenergetics, signaling and manipulation for therapy. Biochim Biophys Acta. (2016) 1864:1787800. doi: 10.1016/j.bbapap.2016.06.014

34. Green RM, Graham M, O'Donovan MR, Chipman JK, Hodges NJ. Subcellular compartmentalization of glutathione: correlations with parameters of oxidative stress related to genotoxicity. Mutagenesis. (2006) 21:383-90. doi: 10.1093/mutage/gel043

35. Morgan B, Ezerina D, Amoako TN, Riemer J, Seedorf M, Dick TP. Multiple glutathione disulfide removal pathways mediate cytosolic redox homeostasis. Nat Chem Biol. (2013) 9:119-25. doi: 10.1038/nchembio.1142

36. Xiao W, Wang RS, Handy DE, Loscalzo J. NAD $(H)$ and $\mathrm{NADP}(\mathrm{H})$ redox couples and cellular energy metabolism. Antioxid Redox Signal. (2018) 28:251-72. doi: 10.1089/ars.2017.7216

37. Zhao Y, Zhang Z, Zou Y, Yang Y. Visualization of nicotine adenine dinucleotide redox homeostasis with genetically encoded fluorescent sensors. Antioxid Redox Signal. (2018) 28:213-29. doi: 10.1089/ars.2017.7226

38. Berger F, Ramirez-Hernandez MH, Ziegler M. The new life of a centenarian: signalling functions of NAD(P). Trends Biochem Sci. (2004) 29:1118. doi: 10.1016/j.tibs.2004.01.007

39. Di Stefano M, Conforti L. Diversification of NAD biological role: the importance of location. FEBS J. (2013) 280:4711-28. doi: 10.1111/febs.12433

40. Hassinen IE. Signaling and regulation through the $\mathrm{NAD}(+)$ and $\mathrm{NADP}(+)$ networks. Antioxid Redox Signal. (2019) 30:85774. doi: 10.1089 /ars.2017.7479

41. Chiarugi A, Dolle C, Felici R, Ziegler M. The NAD metabolome-a key determinant of cancer cell biology. Nat Rev Cancer. (2012) 12:74152. doi: $10.1038 / \mathrm{nrc} 3340$

42. Audrito V, Manago A, Gaudino F, Sorci L, Messana VG, Raffaelli N, et al. NAD-biosynthetic and consuming enzymes as central players of metabolic regulation of innate and adaptive immune responses in cancer. Front Immunol. (2019) 10:1720. doi: 10.3389/fimmu.2019.01720

43. Canto C, Menzies KJ, Auwerx J. NAD(+) metabolism and the control of energy homeostasis: a balancing act between mitochondria and the nucleus. Cell Metab. (2015) 22:31-53. doi: 10.1016/j.cmet.2015.05.023

44. O'Reilly T, Niven DF. Levels of nicotinamide adenine dinucleotide in extracellular body fluids of pigs may be growth-limiting for Actinobacillus pleuropneumoniae and Haemophilus parasuis. Can J Vet Res. (2003) 67:22931.

45. Billington RA, Bruzzone S, De Flora A, Genazzani AA, Koch-Nolte F, Ziegler $\mathrm{M}$, et al. Emerging functions of extracellular pyridine nucleotides. Mol Med. (2006) 12:324-7. doi: 10.2119/2006-00075.Billington

46. Gaudino F, Manfredonia I, Manago A, Audrito V, Raffaelli N, Vaisitti T, et al. Subcellular characterization of nicotinamide adenine dinucleotide biosynthesis in metastatic melanoma by using organelle-specific biosensors. Antioxid Redox Signal. (2019) 31:1150-65. doi: 10.1089/ars.2019.7799

47. Kulkarni CA, Brookes P. Cellular compartmentation and the redox/non-redox functions of NAD. Antioxid Redox Signal. (2019) 31:623-42. doi: 10.1089/ars.2018.7722

48. Bruzzone S, Guida L, Zocchi E, Franco L, De Flora A. Connexin 43 hemi channels mediate $\mathrm{Ca}^{2+}$-regulated transmembrane NAD+ fluxes in intact cells. FASEB J. (2001) 15:10-12. doi: 10.1096/fj.00-0566fje
49. Hwang SJ, Durnin L, Dwyer L, Rhee PL, Ward SM, Koh SD, et al. betanicotinamide adenine dinucleotide is an enteric inhibitory neurotransmitter in human and nonhuman primate colons. Gastroenterology. (2011) 140:60817 e606. doi: 10.1053/j.gastro.2010.09.039

50. Mottahedeh J, Haffner MC, Grogan TR, Hashimoto T, Crowell PD, Beltran $\mathrm{H}$, et al. CD38 is methylated in prostate cancer and regulates extracellular NAD(). Cancer Metab. (2018) 6:13. doi: 10.1186/s40170-018-0186-3

51. Adriouch S, Hubert S, Pechberty S, Koch-Nolte F, Haag F, Seman M. NAD(+) released during inflammation participates in $\mathrm{T}$ cell homeostasis by inducing ART2-mediated death of naive T cells in vivo. J Immunol. (2007) 179:18694. doi: 10.4049/jimmunol.179.1.186

52. Grahnert A, Klein C, Schilling E, Wehrhahn J, Hauschildt S. Review: NAD +: A modulator of immune functions. Innate Immun. (2011) 17:21233. doi: $10.1177 / 1753425910361989$

53. Adriouch S, Haag F, Boyer O, Seman M, Koch-Nolte F. Extracellular $\mathrm{NAD}(+)$ : a danger signal hindering regulatory T cells. Microbes Infect. (2012) 14:1284-92. doi: 10.1016/j.micinf.2012.05.011

54. Takanaga H, Maeda H, Yabuuchi $H$, Tamai I, Higashida H, Tsuji A. Nicotinic acid transport mediated by $\mathrm{pH}$-dependent anion antiporter and proton cotransporter in rabbit intestinal brush-border membrane. J Pharm Pharmacol. (1996) 48:1073-7. doi: 10.1111/j.2042-7158.1996.tb05902.x

55. Said HM, Nabokina SM, Balamurugan K, Mohammed ZM, Urbina C, Kashyap ML. Mechanism of nicotinic acid transport in human liver cells: experiments with HepG2 cells and primary hepatocytes. Am J Physiol Cell Physiol. (2007) 293:C1773-8. doi: 10.1152/ajpcell.00409.2007

56. Hara N, Yamada K, Shibata T, Osago H, Tsuchiya M. Nicotinamide phosphoribosyltransferase/visfatin does not catalyze nicotinamide mononucleotide formation in blood plasma. PLoS ONE. (2011) 6:e22781. doi: 10.1371/journal.pone.0022781

57. Fruscione F, Scarfi S, Ferraris C, Bruzzone S, Benvenuto F, Guida L, et al. Regulation of human mesenchymal stem cell functions by an autocrine loop involving NAD+ release and P2Y11-mediated signaling. Stem Cells Dev. (2011) 20:1183-98. doi: 10.1089/scd.2010.0295

58. Gerth A, Nieber K, Oppenheimer NJ, Hauschildt S. Extracellular NAD+ regulates intracellular free calcium concentration in human monocytes. Biochem J. (2004) 382(Pt 3):849-56. doi: 10.1042/BJ20040979

59. Aswad F, Kawamura H, Dennert G. High sensitivity of CD4+CD25+ regulatory $\mathrm{T}$ cells to extracellular metabolites nicotinamide adenine dinucleotide and ATP: a role for P2X7 receptors. J Immunol. (2005) 175:3075-83. doi: 10.4049/jimmunol.175.5.3075

60. Durnin L, Hwang SJ, Ward SM, Sanders KM, Mutafova-Yambolieva VN. Adenosine 5-diphosphate-ribose is a neural regulator in primate and murine large intestine along with beta-NAD $\left(^{+}\right)$. J Physiol. (2012) 590(Pt 8):192141. doi: 10.1113/jphysiol.2011.222414

61. Deaglio S, Robson SC. Ectonucleotidases as regulators of purinergic signaling in thrombosis, inflammation, and immunity. Adv Pharmacol. (2011) 61:30132. doi: 10.1016/B978-0-12-385526-8.00010-2

62. Deaglio S, Malavasi F. The CD38/CD157 mammalian gene family: an evolutionary paradigm for other leukocyte surface enzymes. Purinerg Signal. (2006) 2:431-41. doi: 10.1007/s11302-006-9002-6

63. Chini EN. CD38 as a regulator of cellular NAD: a novel potential pharmacological target for metabolic conditions. Curr Pharm Des. (2009) 15:57-63. doi: 10.2174/138161209787185788

64. Seman M, Adriouch S, Haag F, Koch-Nolte F. Ecto-ADP-ribosyltransferases (ARTs): emerging actors in cell communication and signaling. Curr Med Chem. (2004) 11:857-72. doi: 10.2174/0929867043455611

65. Katada T, Kontani K, Wada T, Hosoda N, Hoshino S, Nishina H. Enzymic and signal transduction properties of CD38/NADase and PC-1/phosphodiesterase. Chem Immunol. (2000) 75:6078. doi: $10.1159 / 000058762$

66. Garavaglia S, Bruzzone S, Cassani C, Canella L, Allegrone G, Sturla L, et al. The high-resolution crystal structure of periplasmic Haemophilus influenzae NAD nucleotidase reveals a novel enzymatic function of human CD73 related to NAD metabolism. Biochem J. (2012) 441:13141. doi: $10.1042 / B J 20111263$

67. Horenstein AL, Chillemi A, Zaccarello G, Bruzzone S, Quarona V, Zito A, et al. A CD38/CD203a/CD73 ectoenzymatic pathway independent 
of CD39 drives a novel adenosinergic loop in human T lymphocytes. Oncoimmunology. (2013) 2:e26246. doi: 10.4161/onci.26246

68. Vaisitti T, Arruga F, Guerra G, Deaglio S. Ectonucleotidases in blood malignancies: a tale of surface markers and therapeutic targets. Front Immunol. (2019) 10:2301. doi: 10.3389/fimmu.2019.02301

69. Camacho-Pereira J, Tarrago MG, Chini, C.C. S., Nin V, Escande C, Warner $\mathrm{GM}$, et al. CD38 dictates age-related NAD decline and mitochondrial dysfunction through an SIRT3-dependent mechanism. Cell Metab. (2016) 23:1127-39. doi: 10.1016/j.cmet.2016.05.006

70. Grozio A, Sociali G, Sturla L, Caffa I, Soncini D, Salis A, et al. CD73 protein as a source of extracellular precursors for sustained NAD+ biosynthesis in FK866-treated tumor cells. J Biol Chem. (2013) 288:2593849. doi: $10.1074 /$ jbc.M113.470435

71. Nikiforov A, Dolle C, Niere M, Ziegler M. Pathways and subcellular compartmentation of NAD biosynthesis in human cells: from entry of extracellular precursors to mitochondrial NAD generation. J Biol Chem. (2011) 286:21767-78. doi: 10.1074/jbc.M110.213298

72. Ratajczak J, Joffraud M, Trammell SA, Ras R, Canela N, Boutant M, et al. NRK1 controls nicotinamide mononucleotide and nicotinamide riboside metabolism in mammalian cells. Nat Commun. (2016) 7:13103. doi: $10.1038 /$ ncomms 13103

73. Grozio A, Mills KF, Yoshino J, Bruzzone S, Sociali G, Tokizane K, et al. Slc12a8 is a nicotinamide mononucleotide transporter. Nat Metab. (2019) 1:47-57. doi: 10.1038/s42255-018-0009-4

74. Nakahata Y, Sahar S, Astarita G, Kaluzova M, Sassone-Corsi P. Circadian control of the NAD+ salvage pathway by CLOCK-SIRT1. Science. (2009) 324:654-7. doi: 10.1126/science.1170803

75. Ramsey KM, Yoshino J, Brace CS, Abrassart D, Kobayashi Y, Marcheva B, et al. Circadian clock feedback cycle through NAMPT-mediated NAD+ biosynthesis. Science. (2009) 324:651-4. doi: 10.1126/science.1171641

76. Bogan KL, Brenner C. Nicotinic acid, nicotinamide, and nicotinamide riboside: a molecular evaluation of NAD+ precursor vitamins in human nutrition. Annu Rev Nutr. (2008) 28:115-30. doi: 10.1146/annurev.nutr.28.061807.155443

77. Sauve AA. NAD+ and vitamin B3: from metabolism to therapies. $J$ Pharmacol Exp Ther. (2008) 324:883-93. doi: 10.1124/jpet.107.120758

78. Rongvaux A, Andris F, Van Gool F, Leo O. Reconstructing eukaryotic NAD metabolism. Bioessays. (2003) 25:683-90. doi: 10.1002/bies.10297

79. Revollo JR, Korner A, Mills KF, Satoh A, Wang T, Garten A, et al. Nampt/PBEF/Visfatin regulates insulin secretion in beta cells as a systemic NAD biosynthetic enzyme. Cell Metab. (2007) 6:363-75. doi: 10.1016/j.cmet.2007.09.003

80. Pissios P. Nicotinamide $\mathrm{N}$-methyltransferase: more than a vitamin B3 clearance enzyme. Trends Endocrinol Metab. (2017) 28:340-53. doi: 10.1016/j.tem.2017.02.004

81. Bockwoldt M, Houry D, Niere M, Gossmann TI, Reinartz I, Schug A, et al. Identification of evolutionary and kinetic drivers of NADdependent signaling. Proc Natl Acad Sci USA. (2019) 116:1595766. doi: $10.1073 /$ pnas. 1902346116

82. Khan JA, Tao X, Tong L. Molecular basis for the inhibition of human NMPRTase, a novel target for anticancer agents. Nat Struct Mol Biol. (2006) 13:582-8. doi: 10.1038/nsmb1105

83. Wang T, Zhang X, Bheda P, Revollo JR, Imai S, Wolberger C. Structure of Nampt/PBEF/visfatin, a mammalian NAD+ biosynthetic enzyme. Nat Struct Mol Biol. (2006) 13:661-2. doi: 10.1038/nsmb1114

84. Sociali G, Grozio A, Caffa I, Schuster S, Becherini P, Damonte P, et al. SIRT6 deacetylase activity regulates NAMPT activity and $\mathrm{NAD}(\mathrm{P})(\mathrm{H})$ pools in cancer cells. FASEB J. (2019) 33:3704-17. doi: 10.1096/fj.201800321R

85. Galassi L, Di Stefano M, Brunetti L, Orsomando G, Amici A, Ruggieri $\mathrm{S}$, et al. Characterization of human nicotinate phosphoribosyltransferase: kinetic studies, structure prediction and functional analysis by site-directed mutagenesis. Biochimie. (2012) 94:300-9. doi: 10.1016/j.biochi.2011.06.033

86. Zamporlini F, Ruggieri S, Mazzola F, Amici A, Orsomando G, Raffaelli N. Novel assay for simultaneous measurement of pyridine mononucleotides synthesizing activities allows dissection of the NAD biosynthetic machinery in mammalian cells. FEBS J. (2014) 281:5104-19. doi: 10.1111/febs.13050

87. Collins $\mathrm{PB}, \mathrm{Chaykin} \mathrm{S}$. The management of nicotinamide and nicotinic acid in the mouse. J Biol Chem. (1972) 247:778-83.
88. Duarte-Pereira S, Pereira-Castro I, Silva SS, Correia MG, Neto C, da Costa LT, et al. Extensive regulation of nicotinate phosphoribosyltransferase (NAPRT) expression in human tissues and tumors. Oncotarget. (2016) 7:1973-83. doi: 10.18632/oncotarget.6538

89. Gaut ZN, Solomon HM. Inhibition of nicotinate phosphoribosyltransferase in human platelet lysate by nicotinic acid analogs. Biochem Pharmacol. (1971) 20:2903-6. doi: 10.1016/0006-2952(71)90202-4

90. Smith LD, Gholson RK. Allosteric properties of bovine liver nicotinate phosphoribosyltransferase. J Biol Chem. (1969) 244:68-71.

91. Marletta AS, Massarotti A, Orsomando G, Magni G, Rizzi M, Garavaglia S. Crystal structure of human nicotinic acid phosphoribosyltransferase. FEBS Open Biol. (2015) 5:419-28. doi: 10.1016/j.fob.2015.05.002

92. Berger F, Lau C, Dahlmann M, Ziegler M. Subcellular compartmentation and differential catalytic properties of the three human nicotinamide mononucleotide adenylyltransferase isoforms. J Biol Chem. (2005) 280:36334-41. doi: 10.1074/jbc.M508660200

93. Stein LR, Imai $S$. The dynamic regulation of NAD metabolism in mitochondria. Trends Endocrinol Metab. (2012) 23:4208. doi: 10.1016/j.tem.2012.06.005

94. Martin PR, Shea RJ, Mulks MH. Identification of a plasmid-encoded gene from Haemophilus ducreyi which confers NAD independence. J Bacteriol. (2001) 183:1168-74. doi: 10.1128/JB.183.4.1168-1174.2001

95. Muller WE, Perovic S, Wilkesman J, Kruse M, Muller IM, Batel R. Increased gene expression of a cytokine-related molecule and profilin after activation of Suberites domuncula cells with xenogeneic sponge molecule(s). DNA Cell Biol. (1999) 18:885-93. doi: 10.1089/104454999314746

96. Fujiki K, Shin DH, Nakao M, Yano T. Molecular cloning and expression analysis of the putative carp (Cyprinus carpio) pre-B cell enhancing factor. Fish Shellfish Immunol. (2000) 10:383-5. doi: 10.1006/fsim. 2000.0263

97. McGlothlin JR, Gao L, Lavoie T, Simon BA, Easley RB, Ma SF, et al. Molecular cloning and characterization of canine pre-B-cell colony-enhancing factor. Biochem Genet. (2005) 43:127-41. doi: 10.1007/s10528-005-1505-2

98. Rongvaux A, Shea RJ, Mulks MH, Gigot D, Urbain J, Leo O, et al. Pre-B-cell colony-enhancing factor, whose expression is up-regulated in activated lymphocytes, is a nicotinamide phosphoribosyltransferase, a cytosolic enzyme involved in NAD biosynthesis. Eur J Immunol. (2002) 32:322534. doi: 10.1002/1521-4141(200211)32:11<3225::AID-IMMU3225>3.0. $\mathrm{CO} ; 2-\mathrm{L}$

99. Samal B, Sun Y, Stearns G, Xie C, Suggs S, McNiece I. Cloning and characterization of the cDNA encoding a novel human pre-B-cell colony-enhancing factor. Mol Cell Biol. (1994) 14:1431-7. doi: 10.1128/MCB.14.2.1431

100. Grolla AA, Travelli C, Genazzani AA, Sethi JK. Extracellular nicotinamide phosphoribosyltransferase, a new cancer metabokine. Br J Pharmacol. (2016) 173:2182-94. doi: 10.1111/bph.13505

101. Ognjanovic S, Bao S, Yamamoto SY, Garibay-Tupas J, Samal B, BryantGreenwood GD. Genomic organization of the gene coding for human preB-cell colony enhancing factor and expression in human fetal membranes. $J$ Mol Endocrinol. (2001) 26:107-17. doi: 10.1677/jme.0.0260107

102. Zhang LQ, Heruth DP, Ye SQ. Nicotinamide phosphoribosyltransferase in human diseases. J Bioanal Biomed. (2011) 3:1325. doi: 10.4172/1948-593X.1000038

103. Nowell MA, Richards PJ, Fielding CA, Ognjanovic S, Topley N, Williams AS, et al. Regulation of pre-B cell colony-enhancing factor by STAT-3-dependent interleukin-6 trans-signaling: implications in the pathogenesis of rheumatoid arthritis. Arthritis Rheum. (2006) 54:208495. doi: 10.1002/art.21942

104. Bae SK, Kim SR, Kim JG, Kim JY, Koo TH, Jang HO, et al. Hypoxic induction of human visfatin gene is directly mediated by hypoxia-inducible factor-1. FEBS Lett. (2006) 580:4105-13. doi: 10.1016/j.febslet.2006.06.052

105. Luk T, Malam Z, Marshall JC. Pre-B cell colony-enhancing factor (PBEF)/visfatin: a novel mediator of innate immunity. J Leukoc Biol. (2008) 83:804-16. doi: $10.1189 / \mathrm{jlb} .0807581$

106. Chowdhry S, Zanca C, Rajkumar U, Koga T, Diao Y, Raviram $\mathrm{R}$, et al. NAD metabolic dependency in cancer is shaped by gene amplification and enhancer remodelling. Nature. (2019) 569:570-5. doi: 10.1038/s41586-019-1150-2 
107. Duarte-Pereira S, Silva SS, Azevedo L, Castro L, Amorim A, Silva RM. NAMPT and NAPRT1: novel polymorphisms and distribution of variants between normal tissues and tumor samples. Sci Rep. (2014) 4:6311. doi: 10.1038/srep06311

108. Kitani T, Okuno S, Fujisawa H. Growth phase-dependent changes in the subcellular localization of pre-B-cell colony-enhancing factor. FEBS Lett. (2003) 544:74-78. doi: 10.1016/S0014-5793(03)00476-9

109. Pittelli M, Formentini L, Faraco G, Lapucci A, Rapizzi E, Cialdai F, et al. Inhibition of nicotinamide phosphoribosyltransferase: cellular bioenergetics reveals a mitochondrial insensitive NAD pool. J Biol Chem. (2010) 285:34106-114. doi: 10.1074/jbc.M110.136739

110. Zhu Y, Liu J, Park J, Rai P, Zhai RG. Subcellular compartmentalization of $\mathrm{NAD}(+)$ and its role in cancer: A sereNADe of metabolic melodies. Pharmacol Ther. (2019) 200:27-41. doi: 10.1016/j.pharmthera.2019. 04.002

111. Svoboda P, Krizova E, Sestakova S, Vapenkova K, Knejzlik Z, Rimpelova S, et al. Nuclear transport of nicotinamide phosphoribosyltransferase is cell cycle-dependent in mammalian cells, and its inhibition slows cell growth. J Biol Chem. (2019) 294:8676-89. doi: 10.1074/jbc.RA118.003505

112. Grolla AA, Miggiano R, Di Marino D, Bianchi M, Gori A, Orsomando $\mathrm{G}$, et al. A nicotinamide phosphoribosyltransferase-GAPDH interaction sustains the stress-induced $\mathrm{NMN} / \mathrm{NAD}(+)$ salvage pathway in the nucleus. $J$ Biol Chem. (2020) 295:3635-51. doi: 10.1074/jbc.RA119.010571

113. Tanaka M, Nozaki M, Fukuhara A, Segawa K, Aoki N, Matsuda $\mathrm{M}$, et al. Visfatin is released from 3T3-L1 adipocytes via a nonclassical pathway. Biochem Biophys Res Commun. (2007) 359:194201. doi: 10.1016/j.bbrc.2007.05.096

114. Garten A, Petzold S, Barnikol-Oettler A, Korner A, Thasler WE, Kratzsch J, et al. Nicotinamide phosphoribosyltransferase (NAMPT/PBEF/visfatin) is constitutively released from human hepatocytes. Biochem Biophys Res Commun. (2010) 391:376-81. doi: 10.1016/j.bbrc.2009.11.066

115. Friebe D, Neef M, Kratzsch J, Erbs S, Dittrich K, Garten A, et al. Leucocytes are a major source of circulating nicotinamide phosphoribosyltransferase (NAMPT)/pre-B cell colony (PBEF)/visfatin linking obesity and inflammation in humans. Diabetologia. (2011) 54:1200-11. doi: 10.1007/s00125-010-2042-Z

116. Schilling E, Wehrhahn J, Klein C, Raulien N, Ceglarek U, Hauschildt S. Inhibition of nicotinamide phosphoribosyltransferase modifies LPSinduced inflammatory responses of human monocytes. Innate Immun. (2012) 18:518-30. doi: 10.1177/1753425911423853

117. Pillai VB, Sundaresan NR, Kim G, Samant S, Moreno-Vinasco L, Garcia JG, et al. Nampt secreted from cardiomyocytes promotes development of cardiac hypertrophy and adverse ventricular remodeling. Am J Physiol Heart Circ Physiol. (2013) 304:H415-26. doi: 10.1152/ajpheart.00468.2012

118. Grolla AA, Torretta S, Gnemmi I, Amoruso A, Orsomando G, Gatti M, et al. Nicotinamide phosphoribosyltransferase (NAMPT/PBEF/visfatin) is a tumoural cytokine released from melanoma. Pigment Cell Melanoma Res. (2015) 28:718-29. doi: 10.1111/pcmr.12420

119. Audrito V, Manago A, Zamporlini F, Rulli E, Gaudino F, Madonna G, et al. Extracellular nicotinamide phosphoribosyltransferase (eNAMPT) is a novel marker for patients with BRAF-mutated metastatic melanoma. Oncotarget. (2018) 9:18997-9005. doi: 10.18632/oncotarget.24871

120. Yoshida M, Satoh A, Lin JB, Mills KF, Sasaki Y, Rensing N, et al. Extracellular vesicle-contained eNAMPT delays aging and extends lifespan in mice. Cell Metab. (2019) 30:329-42 e325. doi: 10.1016/j.cmet.2019.05.015

121. Lu YB, Chen CX, Huang J, Tian YX, Xie X, Yang P, et al. Nicotinamide phosphoribosyltransferase secreted from microglia via exosome during ischemic injury. J Neurochem. (2019) 150:723-37. doi: 10.1111/jnc.14811

122. Yoon MJ, Yoshida M, Johnson S, Takikawa A, Usui I, Tobe K, et al. SIRT1-mediated eNAMPT secretion from adipose tissue regulates hypothalamic NAD+ and function in mice. Cell Metab. (2015) 21:70617. doi: 10.1016/j.cmet.2015.04.002

123. Piacente F, Caffa I, Ravera S, Sociali G, Passalacqua M, Vellone VG, et al. Nicotinic acid phosphoribosyltransferase regulates cancer cell metabolism, susceptibility to NAMPT inhibitors, and DNA repair. Cancer Res. (2017) 77:3857-69. doi: 10.1158/0008-5472.CAN-16-3079

124. Manago A, Audrito V, Mazzola F, Sorci L, Gaudino F, Gizzi K, et al. Extracellular nicotinate phosphoribosyltransferase binds Toll like receptor 4 and mediates inflammation. Nat Commun. (2019) 10:4116. doi: 10.1038/s41467-019-12055-2

125. O’Brien T, Oeh J, Xiao Y, Liang X, Vanderbilt A, Qin A, et al. Supplementation of nicotinic acid with NAMPT inhibitors results in loss of in vivo efficacy in NAPRT1-deficient tumor models. Neoplasia. (2013) 15:1314-29. doi: 10.1593/neo.131718

126. Shames DS, Elkins K, Walter K, Holcomb T, Du P, Mohl D, et al. Loss of NAPRT1 expression by tumor-specific promoter methylation provides a novel predictive biomarker for NAMPT inhibitors. Clin Cancer Res. (2013) 19:6912-23. doi: 10.1158/1078-0432.CCR-13-1186

127. Sun Z, Lei H, Zhang Z. Pre-B cell colony enhancing factor (PBEF), a cytokine with multiple physiological functions. Cytokine Growth Factor Rev. (2013) 24:433-42. doi: 10.1016/j.cytogfr.2013.05.006

128. Iqbal J, Zaidi $M$. TNF regulates cellular NAD + metabolism in primary macrophages. Biochem Biophys Res Commun. (2006) 342:1312-8. doi: 10.1016/j.bbrc.2006.02.109

129. Gosset M, Berenbaum F, Salvat C, Sautet A, Pigenet A, Tahiri K, et al. Crucial role of visfatin/pre-B cell colony-enhancing factor in matrix degradation and prostaglandin E2 synthesis in chondrocytes: possible influence on osteoarthritis. Arthritis Rheum. (2008) 58:1399-409. doi: 10.1002/art.23431

130. Moschen AR, Gerner RR, Tilg H. Pre-B cell colony enhancing factor/NAMPT/visfatin in inflammation and obesity-related disorders. Curr Pharm Des. (2010) 16:1913-20. doi: 10.2174/138161210791208947

131. Li Y, Zhang Y, Dorweiler B, Cui D, Wang T, Woo CW, et al. Extracellular Nampt promotes macrophage survival via a nonenzymatic interleukin-6/STAT3 signaling mechanism. J Biol Chem. (2008) 283:3483343. doi: 10.1074/jbc.M805866200

132. Audrito V, Serra S, Brusa D, Mazzola F, Arruga F, Vaisitti T, et al. Extracellular nicotinamide phosphoribosyltransferase (NAMPT) promotes M2 macrophage polarization in chronic lymphocytic leukemia. Blood. (2015) 125:111-23. doi: 10.1182/blood-2014-07-589069

133. Moschen AR, Kaser A, Enrich B, Mosheimer B, Theurl M, Niederegger $\mathrm{H}$, et al. Visfatin, an adipocytokine with proinflammatory and immunomodulating properties. J Immunol. (2007) 178:174858. doi: 10.4049/jimmunol.178.3.1748

134. Fan Y, Meng S, Wang Y, Cao J, Wang C. Visfatin/PBEF/Nampt induces EMMPRIN and MMP-9 production in macrophages via the NAMPT-MAPK (p38, ERK1/2)-NF-kappaB signaling pathway. Int J Mol Med. (2011) 27:60715. doi: 10.3892/ijmm.2011.621

135. Chang YC, Chang TJ, Lee WJ, Chuang LM. The relationship of visfatin/preB-cell colony-enhancing factor/nicotinamide phosphoribosyltransferase in adipose tissue with inflammation, insulin resistance, and plasma lipids. Metabolism. (2010) 59:93-9. doi: 10.1016/j.metabol.2009.07.011

136. Stephens JM, Vidal-Puig AJ. An update on visfatin/pre-B cell colony-enhancing factor, an ubiquitously expressed, illusive cytokine that is regulated in obesity. Curr Opin Lipidol. (2006) 17:128-31. doi: 10.1097/01.mol.0000217893.77746.4b

137. Araki S, Dobashi K, Kubo K, Kawagoe R, Yamamoto Y, Kawada $\mathrm{Y}$, et al. Plasma visfatin concentration as a surrogate marker for visceral fat accumulation in obese children. Obesity. (2008) 16:3848. doi: 10.1038/oby.2007.54

138. Yoshino J, Mills KF, Yoon MJ, Imai S. Nicotinamide mononucleotide, a key $\mathrm{NAD}(+)$ intermediate, treats the pathophysiology of diet- and age-induced diabetes in mice. Cell Metab. (2011) 14:528-36. doi: 10.1016/j.cmet.2011.08.014

139. Adya R, Tan BK, Punn A, Chen J, Randeva HS. Visfatin induces human endothelial VEGF and MMP-2/9 production via MAPK and PI3K/Akt signalling pathways: novel insights into visfatin-induced angiogenesis. Cardiovasc Res. (2008) 78:356-65. doi: 10.1093/cvr/cvm111

140. Kim SR, Bae YH, Bae SK, Choi KS, Yoon KH, Koo TH, et al. Visfatin enhances ICAM-1 and VCAM-1 expression through ROS-dependent NFkappaB activation in endothelial cells. Biochim Biophys Acta. (2008) 1783:886-95. doi: 10.1016/j.bbamcr.2008.01.004

141. Lovren F, Pan Y, Shukla PC, Quan A, Teoh H, Szmitko PE, et al. Visfatin activates eNOS via Akt and MAP kinases and improves endothelial cell function and angiogenesis in vitro and in vivo: translational implications for atherosclerosis. Am J Physiol Endocrinol Metab. (2009) 296:E14409. doi: 10.1152/ajpendo.90780.2008 
142. Romacho T, Azcutia V, Vazquez-Bella M, Matesanz N, Cercas E, Nevado J, et al. Extracellular PBEF/NAMPT/visfatin activates proinflammatory signalling in human vascular smooth muscle cells through nicotinamide phosphoribosyltransferase activity. Diabetologia. (2009) 52:2455-63. doi: 10.1007/s00125-009-1509-2

143. Adya R, Tan BK, Chen J, Randeva HS. Pre-B cell colony enhancing factor (PBEF)/visfatin induces secretion of MCP-1 in human endothelial cells: role in visfatin-induced angiogenesis. Atherosclerosis. (2009) 205:1139. doi: 10.1016/j.atherosclerosis.2008.11.024

144. Bae YH, Bae MK, Kim SR, Lee JH, Wee HJ, Bae SK. Upregulation of fibroblast growth factor-2 by visfatin that promotes endothelial angiogenesis. Biochem Biophys Res Commun. (2009) 379:206-11. doi: 10.1016/j.bbrc.2008. 12.042

145. Venereau E, Ceriotti C, Bianchi ME. DAMPs from cell death to new life. Front Immunol. (2015) 6:422. doi: 10.3389/fimmu.2015.00422

146. Travelli C, Colombo G, Mola S, Genazzani AA, Porta C. NAMPT: a pleiotropic modulator of monocytes and macrophages. Pharmacol Res. (2018) 135:25-36. doi: 10.1016/j.phrs.2018.06.022

147. Minhas PS, Liu L, Moon PK, Joshi AU, Dove C, Mhatre S, et al. Macrophage de novo $\mathrm{NAD}(+)$ synthesis specifies immune function in aging and inflammation. Nat Immunol. (2019) 20:50-63. doi: 10.1038/s41590-018-0255-3

148. Skokowa J, Lan D, Thakur BK, Wang F, Gupta K, Cario G, et al. NAMPT is essential for the G-CSF-induced myeloid differentiation via a $\mathrm{NAD}(+)$-sirtuin-1-dependent pathway. Nat Med. (2009) 15:1518. doi: 10.1038/nm.1913

149. Travelli C, Consonni FM, Sangaletti S, Storto M, Morlacchi S, Grolla AA, et al. Nicotinamide phosphoribosyltransferase (NAMPT) acts as a metabolic gate for mobilization of myeloid-derived suppressor cells. Cancer Res. (2019) 79:1938-51. doi: 10.1158/0008-5472.CAN-18-1544

150. Weidemann A, Johnson RS. Biology of HIF-1alpha. Cell Death Differ. (2008) 15:621-7. doi: $10.1038 / \mathrm{cdd} .2008 .12$

151. Gleyzer N, Scarpulla RC. PGC-1-related coactivator (PRC), a sensor of metabolic stress, orchestrates a redox-sensitive program of inflammatory gene expression. J Biol Chem. (2011) 286:39715-25. doi: 10.1074/jbc.M111.291575

152. Liu TF, Vachharajani VT, Yoza BK, McCall CE. NAD+-dependent sirtuin 1 and 6 proteins coordinate a switch from glucose to fatty acid oxidation during the acute inflammatory response. J Biol Chem. (2012) 287:2575869. doi: 10.1074/jbc.M112.362343

153. Fernandes CA, Fievez L, Neyrinck AM, Delzenne NM, Bureau F, Vanbever R. Sirtuin inhibition attenuates the production of inflammatory cytokines in lipopolysaccharide-stimulated macrophages. Biochem Biophys Res Commun. (2012) 420:857-61. doi: 10.1016/j.bbrc.2012.03.088

154. Koch C, Samareh B, Morishima T, Mir P, Kanz L, Zeidler C, et al. GMCSF treatment is not effective in congenital neutropenia patients due to its inability to activate NAMPT signaling. Ann Hematol. (2017) 96:34553. doi: 10.1007/s00277-016-2894-5

155. Molugu TR, Oita RC, Chawla U, Camp SM, Brown MF, Garcia, GN, et al. (2020) Nicotinamide phosphoribosyltransferase purification using SUMO expression system. Anal Biochem, 113597. doi: 10.1016/j.ab.2020.113597

156. Yang K, Lauritzen KH, Olsen MB, Dahl TB, Ranheim T, Ahmed $\mathrm{MS}$, et al. Low cellular $\mathrm{NAD}(+)$ compromises lipopolysaccharideinduced inflammatory responses via inhibiting TLR4 signal transduction in human monocytes. J Immunol. (2019) 203:1598608. doi: 10.4049/jimmunol.1801382

157. Chang YH, Chang DM, Lin KC, Shin SJ, Lee YJ. Visfatin in overweight/obesity, type 2 diabetes mellitus, insulin resistance, metabolic syndrome and cardiovascular diseases: a meta-analysis and systemic review. Diabetes Metab Res Rev. (2011) 27:515-27. doi: 10.1002/dmrr.1201

158. Romacho T, Sanchez-Ferrer CF, Peiro C. Visfatin/Nampt: an adipokine with cardiovascular impact. Mediators Inflamm. (2013) 2013:946427. doi: 10.1155/2013/946427

159. Chen X, Zhao S, Song Y, Shi Y, Leak RK, Cao G. The role of nicotinamide phosphoribosyltransferase in cerebral ischemia. Curr Top Med Chem. (2015) 15:2211-2221. doi: 10.2174/1568026615666150610142234

160. Wang P, Miao CY. NAMPT as a therapeutic target against stroke. Trends Pharmacol Sci. (2015) 36:891-905. doi: 10.1016/j.tips.2015.08.012
161. Malyszko J, Malyszko JS, Mysliwiec M. Visfatin, a new adipocytokine, is predominantly related to inflammation/endothelial damage in kidney allograft recipients. TransplProc. (2009) 41:150-3. doi: 10.1016/j.transproceed.2008.10.086

162. Dambala K, Vavilis D, Bili E, Goulis DG, Tarlatzis BC. Serum visfatin, vascular endothelial growth factor and matrix metalloproteinase-9 in women with polycystic ovary syndrome. Gynecol Endocrinol. (2017) 33:52933. doi: 10.1080/09513590.2017.1296425

163. Porter B, Babbar S, Ye SQ, Maulik D. The role of nicotinamide phosphoribosyltransferase in pregnancy: a review. Am J Perinatol. (2016) 33:1327-36. doi: 10.1055/s-0036-1582448

164. Dahl TB, Yndestad A, Skjelland M, Oie E, Dahl A, Michelsen $A$, et al. Increased expression of visfatin in macrophages of human unstable carotid and coronary atherosclerosis: possible role in inflammation and plaque destabilization. Circulation. (2007) 115:972-80. doi: 10.1161/CIRCULATIONAHA.106.665893

165. Ye SQ, Simon BA, Maloney JP, Zambelli-Weiner A, Gao L, Grant A, et al. Pre-B-cell colony-enhancing factor as a potential novel biomarker in acute lung injury. Am J Respir Crit Care Med. (2005) 171:36170. doi: 10.1164/rccm.200404-563OC

166. Moreno-Vinasco L, Quijada H, Sammani S, Siegler J, Letsiou E, Deaton $\mathrm{R}$, et al. Nicotinamide phosphoribosyltransferase inhibitor is a novel therapeutic candidate in murine models of inflammatory lung injury. Am J Respir Cell Mol Biol. (2014) 51:223-8. doi: 10.1165/rcmb.2012-0519OC

167. Jia SH, Li Y, Parodo J, Kapus A, Fan L, Rotstein OD, et al. Pre-B cell colonyenhancing factor inhibits neutrophil apoptosis in experimental inflammation and clinical sepsis. J Clin Invest. (2004) 113:1318-27. doi: 10.1172/JCI19930

168. Karampela I, Christodoulatos GS, Kandri E, Antonakos G, Vogiatzakis E, Dimopoulos G, et al. Circulating eNampt and resistin as a proinflammatory duet predicting independently mortality in critically ill patients with sepsis: a prospective observational study. Cytokine. (2019) 119:6270. doi: 10.1016/j.cyto.2019.03.002

169. Ognjanovic S, Bryant-Greenwood GD. Pre-B-cell colony-enhancing factor, a novel cytokine of human fetal membranes. Am J Obstet Gynecol. (2002) 187:1051-8. doi: 10.1067/mob.2002.126295

170. Ismail SA, Mohamed SA. Serum levels of visfatin and omentin-1 in patients with psoriasis and their relation to disease severity. Br J Dermatol. (2012) 167:436-9. doi: 10.1111/j.1365-2133.2012.10980.x

171. Franco-Trepat E, Alonso-Perez A, Guillan-Fresco M, Jorge-Mora A, Gualillo O, Gomez-Reino JJ, et al. Visfatin as a therapeutic target for rheumatoid arthritis. Expert Opin Ther Targets. (2019) 23:60718. doi: 10.1080/14728222.2019.1617274

172. Neubauer K, Bednarz-Misa I, Walecka-Zacharska E, Wierzbicki J, Agrawal A, Gamian A, et al. Oversecretion and overexpression of nicotinamide phosphoribosyltransferase/Pre-B colony-enhancing factor/visfatin in inflammatory bowel disease reflects the disease activity, severity of inflammatory response and hypoxia. Int J Mol Sci. (2019) 20:166. doi: 10.3390/ijms20010166

173. Sayers SR, Beavil RL, Fine, NHF, Huang GC, Choudhary P, Pacholarz KJ, et al. Structure-functional changes in eNAMPT at high concentrations mediate mouse and human beta cell dysfunction in type 2 diabetes. Diabetologia. (2019). 63:313-23. doi: 10.1007/s00125-019-05029-y

174. Nielsen KN, Peics J, Ma T, Karavaeva I, Dall M, Chubanava S, et al. NAMPT-mediated $\mathrm{NAD}(+)$ biosynthesis is indispensable for adipose tissue plasticity and development of obesity. Mol Metab. (2018) 11:17888. doi: 10.1016/j.molmet.2018.02.014

175. Wang SN, Miao CY. Targeting NAMPT as a therapeutic strategy against stroke. Stroke Vasc Neurol. (2019) 4:83-9. doi: 10.1136/svn-2018-000199

176. Busso N, Karababa M, Nobile M, Rolaz A, Van Gool F, Galli $M$, et al. Pharmacological inhibition of nicotinamide phosphoribosyltransferase/visfatin enzymatic activity identifies a new inflammatory pathway linked to NAD. PLoS ONE. (2008) 3:e2267. doi: 10.1371/journal.pone.0002267

177. Gerner RR, Klepsch V, Macheiner S, Arnhard K, Adolph TE, Grander C, et al. NAD metabolism fuels human and mouse intestinal inflammation. Gut. (2018) 67:1813-1823. doi: 10.1136/gutjnl-2017-314241

178. Dalamaga M, Christodoulatos GS, Mantzoros CS. The role of extracellular and intracellular Nicotinamide phosphoribosyl-transferase in cancer: 
diagnostic and therapeutic perspectives and challenges. Metabolism. (2018) 82:72-87. doi: 10.1016/j.metabol.2018.01.001

179. Yaku K, Okabe K, Hikosaka K, Nakagawa T. NAD metabolism in cancer therapeutics. Front Oncol. (2018) 8:622. doi: 10.3389/fonc.2018.00622

180. Li XQ, Lei J, Mao LH, Wang QL, Xu F, Ran T, et al. NAMPT and NAPRT, key enzymes in NAD salvage synthesis pathway, are of negative prognostic value in colorectal cancer. Front Oncol. (2019) 9:736. doi: 10.3389/fonc.2019.00736

181. Nacarelli T, Lau L, Fukumoto T, Zundell J, Fatkhutdinov N, Wu S, et al. $\mathrm{NAD}(+)$ metabolism governs the proinflammatory senescence-associated secretome. Nat Cell Biol. (2019) 21:397-407. doi: 10.1038/s41556-019-0287-4

182. Fons NR, Sundaram RK, Breuer GA, Peng S, McLean RL, Kalathil $\mathrm{AN}$, et al. PPM1D mutations silence NAPRT gene expression and confer NAMPT inhibitor sensitivity in glioma. Nat Commun. (2019) 10:3790. doi: 10.1038/s41467-019-11732-6

183. Watson M, Roulston A, Belec L, Billot X, Marcellus R, Bedard $\mathrm{D}$, et al. The small molecule GMX1778 is a potent inhibitor of $\mathrm{NAD}+$ biosynthesis: strategy for enhanced therapy in nicotinic acid phosphoribosyltransferase 1-deficient tumors. Mol Cell Biol. (2009) 29:58725888. doi: 10.1128/MCB.00112-09

184. Olesen UH, Hastrup N, Sehested M. Expression patterns of nicotinamide phosphoribosyltransferase and nicotinic acid phosphoribosyltransferase in human malignant lymphomas. APMIS. (2011) 119:296-303. doi: 10.1111/j.1600-0463.2011.02733.x

185. Cerna D, Li H, Flaherty S, Takebe N, Coleman CN, Yoo SS. Inhibition of nicotinamide phosphoribosyltransferase (NAMPT) activity by small molecule GMX1778 regulates reactive oxygen species (ROS)-mediated cytotoxicity in a p53- and nicotinic acid phosphoribosyltransferase1 (NAPRT1)-dependent manner. J Biol Chem. (2012) 287:22408-17. doi: 10.1074/jbc.M112.357301

186. Hasmann M, Schemainda I. FK866, a highly specific noncompetitive inhibitor of nicotinamide phosphoribosyltransferase, represents a novel mechanism for induction of tumor cell apoptosis. Cancer Res. (2003) 63:7436-42.

187. Olesen UH, Christensen MK, Bjorkling F, Jaattela M, Jensen PB, Sehested M, et al. Anticancer agent CHS-828 inhibits cellular synthesis of NAD. Biochem Biophys Res Commun. (2008) 367:799-804. doi: 10.1016/j.bbrc.2008.01.019
188. Galli U, Travelli C, Massarotti A, Fakhfouri G, Rahimian R, Tron GC, et al. Medicinal chemistry of nicotinamide phosphoribosyltransferase (NAMPT) inhibitors. J Med Chem. (2013) 56:6279-96. doi: 10.1021/jm4 001049

189. Abu Aboud O, Chen CH, Senapedis W, Baloglu E, Argueta C, Weiss RH. Dual and specific inhibition of NAMPT and PAK4 By KPT-9274 decreases kidney cancer growth. Mol Cancer Ther. (2016) 15:211929. doi: 10.1158/1535-7163.MCT-16-0197

190. Sampath D, Zabka TS, Misner DL, O'Brien T, Dragovich PS Inhibition of nicotinamide phosphoribosyltransferase (NAMPT) as a therapeutic strategy in cancer. Pharmacol Ther. (2015) 151:16-31. doi: 10.1016/j.pharmthera.2015.02.004

191. Montecucco F, Cea M, Bauer I, Soncini D, Caffa I, Lasiglie D, et al. Nicotinamide phosphoribosyltransferase (NAMPT) inhibitors as therapeutics: rationales, controversies, clinical experience. Curr Drug Targets. (2013) 14:637-43. doi: 10.2174/1389450111314060003

192. Chen H, Wang S, Zhang H, Nice EC, Huang C. Nicotinamide phosphoribosyltransferase (Nampt) in carcinogenesis: new clinical opportunities. Expert Rev Anticancer Ther. (2016) 16:827-38. doi: 10.1080/14737140.2016.1190649

193. Oita RC, Camp SM, Ma W, Ceco E, Harbeck M, Singleton P, et al. Novel mechanism for nicotinamide phosphoribosyltransferase inhibition of TNFalpha-mediated apoptosis in human lung endothelial cells. Am J Respir Cell Mol Biol. (2018) 59:36-44. doi: 10.1165/rcmb.2017-0155OC

Conflict of Interest: The authors declare that the research was conducted in the absence of any commercial or financial relationships that could be construed as a potential conflict of interest.

Copyright (c) 2020 Audrito, Messana and Deaglio. This is an open-access article distributed under the terms of the Creative Commons Attribution License (CC BY). The use, distribution or reproduction in other forums is permitted, provided the original author(s) and the copyright owner(s) are credited and that the original publication in this journal is cited, in accordance with accepted academic practice. No use, distribution or reproduction is permitted which does not comply with these terms. 